\title{
Review
}

\section{Enantioselective Hydrogenations with Chiral Titanocenes}

\author{
Oleksiy Vassylyev, Anthony Panarello and Johannes G. Khinast* \\ Department of Chemical and Biochemical Engineering, Rutgers University, Piscataway, NJ 08854- \\ 8058, USA. Tel.: (+1) 732-445-2970, Fax: (+1) 732-445-2581 \\ * Author to whom correspondence should be addressed; e-mail khinast@rutgers.edu
}

Received: 20 July 2004 / Accepted: 8 October 2004 / Published: 14 July 2005

\begin{abstract}
In this review article chiral titanocenes and their application for the enantioselective hydrogenations of different unsaturated compounds are discussed, with a special emphasis on the kinetics and the practicality of the developed systems. The nature of enantioselectivity and the hydrogenation mechanisms are reviewed as well. Catalyst immobilization and the different immobilization techniques are examined.
\end{abstract}

Keywords: Titanocenes, hydrogenation, alkenes, imines, ketones.

\section{Introduction}

Chiral compounds are important products or intermediates in the pharmaceutical, agrochemical and fine chemical industries [1], with the world market for chiral fine chemicals and drugs surpassing \$6 billion in 2000 at an annual growth rate significantly larger than $10 \%$ [2]. Thus, the continuous increase in the demand for chiral precursors and chemicals requires the development of clean, costeffective and reliable technology to make these compounds on an industrial scale. Biotechnological processes are used to make many complex chiral molecules, including small-molecule drugs (in contrast to the large-molecule drugs such as proteins and hormones). However, for the synthesis of small-molecule compounds, synthetic chemistry is increasingly accepted as the more effective approach, as it circumvents the drawbacks of biotechnological processes (e.g., low yields, sensitive media, etc.), while building on the rapidly improving skills of synthetic chemists. Chiral catalysts, i.e., compounds that selectively catalyze the formation only of the desired stereoisomer, are important tools for the effective large-scale synthesis of bioactive molecules. Currently the industry (and especially the pharmaceutical one) is witnessing a shift from stoichiometric to chiral catalytic methods, and 
consequently, the development of new chiral catalysts, in combination with skillful reaction engineering, will be the principal method to make complex chiral molecules for future applications.

Chiral reductions are the largest sub-class of chiral reactions that are carried out on an industrial scale. One the most effective routes for the enantioselective synthesis of amines, alcohols and alkanes is the transition-metal-complex-catalyzed hydrogenation of the corresponding prochiral compounds. Among numerous known catalysts for these reactions, metallocenes are one of the most promising types [3-6], as they are strongly unsymmetrical and, thus, reduce the number of possible isomeric catalyst-substrate complexes, leading to excellent enantiocontrol in many cases. In addition, the possibility of restricting the conformational flexibility and the steric bulk by adding substituent or bridges allows the rational design and tailoring of catalytic activity and selectivity. This becomes especially important as computational chemistry is beginning to become a design tool for the development of new chiral catalysts.

Among metallocenes the catalytic activity of titanocenes for hydrogenation reactions is considerably higher than that of other metal complexes [7], which makes these catalysts especially attractive as hydrogenation catalysts. Therefore, the subject of this review is the enantioselective hydrogenation using titanocenes.

\section{Chirality and Synthesis of Titanocene Catalysts}

Achiral titanocene catalysts, i.e., $\left(\eta^{5}-\mathrm{Cp}\right)_{2}$ Ti-units $(\mathrm{Cp}=$ cyclopentadienyl $)$ and their derivatives were first synthesized in the 1950s and 60s. Chirality was only introduced in the 1970s by incorporating asymmetrically disubstituted Cp-type ligands (leading to planar chirality) or chiral Cptype ligands. At the end of the 1970s, bridged ligands were introduced, giving chiral ansa-titanocenes. Finally, the development of new chiral titanocenes from the late $80 \mathrm{~s}$ until the early $21^{\text {st }}$ century has expanded their use in chiral synthetic chemistry.

The chirality of titanocenes is highly complex and derives from various factors. A detailed overview of the origin of chirality in titanocenes is given in [8]. In general, the chirality of titanocenes may be due to coordination of (1) chiral and (2) prochiral ligands to the metal atom, where in the latter case the ligand is achiral but coordination to the metal center leads to a chiral complex. Both types are designated as ligand-derived chirality. Alternatively, the compound may possess metal-centered chirality, if a tetravalent titanium atom coordinates four different ligands, similar to a chiral foursubstituted carbon atom. Some metallocenes can possess both factors [9]. Since most catalysts are dichlorides or difluorides, only ligand-derived chiral complexes are reviewed in this paper. Metalcentered chiral titanocenes are not used for chiral hydrogenations.

An important factor in the chirality of a complex is how the two sides of the $\pi$-face of a ligand are related to each other [8]. Three possibilities exist, i.e., a ligand may be (i) homotopic (faces are equivalent or can be interchanged by rotation around a $\mathrm{C}_{2}$ axis. Example: $\mathrm{Cp}$ ), (ii) enantiotopic (the faces can be interconverted only by reflection through a mirror plane. Example: $\mathrm{Cp}$ with two different substituents, one of them being chiral), and (iii) diastereotopic (no symmetry operations can interconvert the faces. Example: $\mathrm{Cp}$ with two different substituents, one of them being chiral). Combination of two ligands (of either different or the same type) in a complex may lead to a wide variety of different stereoisomers, except for the case of two homotopic ligands, which lead only to one isomeric complex. In the case of diastereotopic ligands the complex has both planar and ligand- 
carbon-centered chirality, which may give up to 11 different isomers. If the ligand itself has more than one chiral center, a larger number of isomeric complexes may be obtained. Bridged ligands can be of either type, depending on the position of the bridge with respect to other substituents. For example, the well-known ethylene-bridged bis(indenyl) titanocene catalyst reported by Brintzinger (compound 14, below) is of type (ii), while a bridged Cp ligand would be of type (i).

In the next sections non-bridged and bridged titanocenes, their preparation and the nature of their active form, are described. The focus is only on $\mathrm{Cp}$ and indenyl ligands, as well as their derivatives, since fluorenyl ligands for chiral reductions have not been reported yet.

\subsection{Unbridged Titanocenes}

Unbridged chiral titanocenes with two cyclopentadienyl-based ligands must have at least one chiral ligand. In the case of achiral unbridged ligands the titanocene will be achiral as well. In the case of a racemic mixture of homotopic ligands with a chiral center, the products are a mixture of mesocompounds and a $(d, l)$ diastereomer pair in a 50:50 ratio. Since the energies of the meso-compound and the $(d, l)$-pair are different, either the meso-structure or the $(d, l)$ pair may be favored. If the ligand is enantiotopic, again a $(d, I)$-pair and a meso-compound are obtained. In the case of a racemic mixture of diastereotopic ligands, a number of different complexes (up to 11) may be formed, depending on the selectivity of the synthesis [9].

The first titanocene containing chiral cyclopentadienyl ligands, 1, was reported by Tirouflet and co-workers [10]. The mixture of racemic-dl pair (one diastereomer is shown in 1a) and meso- (1b) diastereomers was prepared by treatment of the racemic ligand with $\mathrm{TiCl}_{4}$. Since this first report of a chiral titanocene synthesis, a large number of different compounds were obtained. Cesarotti et al. [11] obtained complex 2 containing a single chiral auxiliary attached to one of the cyclopentadienyl ligands. Chiral complexes derived by fusing a cyclopentadiene ring to naturally occurring terpenes (for example, 3-5) were described by Paquette et al. [12]. Chiral titanocenes 6 ( $\mathrm{R}=\mathrm{H}, \mathrm{Me}, \mathrm{I}-\mathrm{Pr}, \mathrm{Ph})$ were obtained using ligands based on the bicyclo[2.2.2] octane framework [13-15]. They were prepared by addition of $\mathrm{TiCl}_{3}$ and $\mathrm{NaH}$ to the lithiated ligand at $-10^{\circ} \mathrm{C}$.

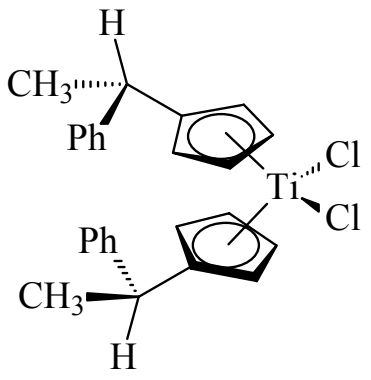

$1 \mathbf{a}$

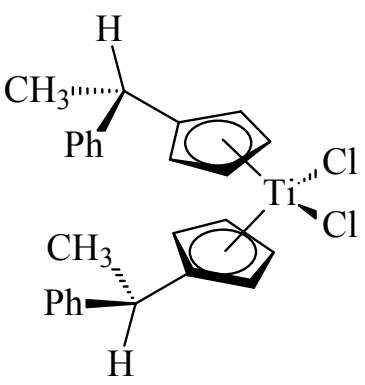

$1 \mathrm{~b}$

Several camphor-derived chiral ligands 7,8 $(\mathrm{R}=\mathrm{Me}, \mathrm{Ph}, \mathrm{t}-\mathrm{Bu})$ were prepared by Nazarov cyclization. Success of the metalation of the ligand depended on the steric hindrances: using $\mathrm{TiCl}_{3}$ as a titanium source, only the least hindered methyl-substituted 7 was successfully converted to titanocene $\mathbf{9}$ as shown in Scheme 1. Complex 10 was not obtained [16]. 


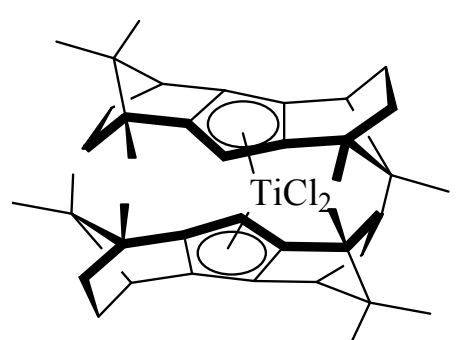

10

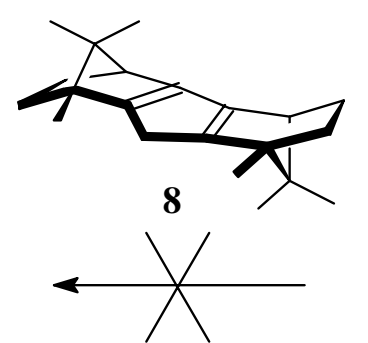

$\mathrm{TiCl}_{3}$



Scheme 1

Metalation of cyclopentadienyl-containing ligands can be carried out in different ways, and most methods for the titanocene synthesis fall into two principal groups: complexation with (i) $\mathrm{TiCl}_{4}$ without oxidation [17,18] or with (ii) $\mathrm{TiCl}_{3}$ [19], followed by oxidation. In both methods, the pentadiene-containing ligand is converted into a lithium or sodium derivative by treatment with $\mathrm{BuLi}$ or $\mathrm{NaH}$, respectively, in ethyl ether or THF. Then, a solution of the titanium salt is added at low temperatures, and the reaction mixture is stirred for several hours. In order to increase the reactivity of the titanium salt, it can be used as a complex with THF [20]. Consecutive addition of chiral and nonchiral cyclopentadienyl anions to the titanium chloride results in asymmetric titanocenes with two different ligands. Separation of the enantiomers can be carried out by selective crystallization of the free isomeric compounds, or by complexation with optically pure compounds [21].

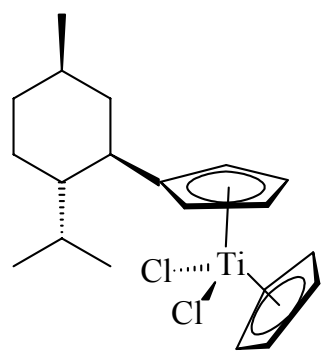

2

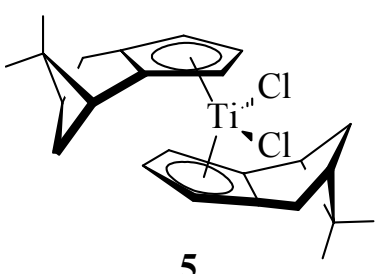

5

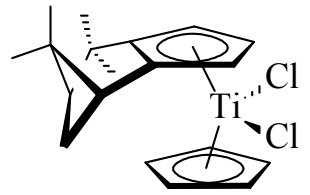

3

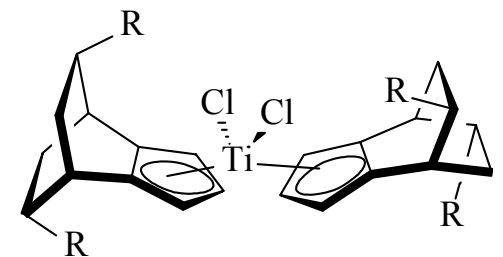

6

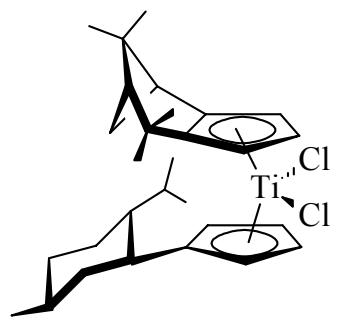

4

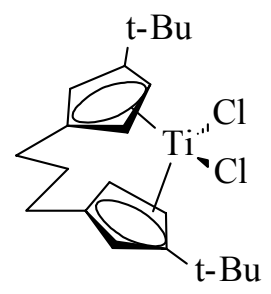

11

\subsection{Ansa-Titanocenes}

The prefix "ansa" is Latin for "bent handle" and is used to describe bridged cyclopentadienederived ligands. Introduction of a bridge between two ligands may lead to a wide variety of different products upon metalation, depending on the nature and location of the bridge in the Cp-type ligand and the chirality of the bridge itself. For example, introduction of a bridge between two achiral ligands can cause chirality of the metalated product. For an excellent review of the chirality of bridged complexes see $[8]$. 
The first and most frequently used method for introducing chirality into ansa-titanocenes is to exploit the chiral orientation of indenyl or substituted pentadienyl ligands connected by a hydrocarbon bridge. The first ansa-titanocenes were obtained from bis-pentadienyl or bis-indenyl ligands [22]. Specifically, the first $\mathrm{C}_{2}$-asymmetric ansa-titanocene $\mathbf{1 1}$ with a propylene bridge was reported in 1979 [23].

Different isomers can be obtained during the metalation of a bridged, achiral ligand. An example is shown in Scheme 2. Since ligand 12 exhibits conformational flexibility, the metalation of the bridged ligand 12 gives two types of product: meso 13 and racemic-dl 14. Subsequently, the desired isomer with $\mathrm{C}_{2}$ symmetry (either $d \mathbf{- 1 4}$ or $\mathbf{l - 1 4}$ ) has to be resolved. Different isomers can also be obtained by different positions of the bridge in the ligands. Ethylene-bridged ansa-bis(tetrahydroindenyl)titanium dichloride 15 was obtained by Brintzinger from the corresponding ligand [24]. Its isomers with different positions of the ethylene bridge in the indene ring and different substituents $(\mathrm{R}=\mathrm{Me}, \mathrm{Bz})$ were prepared by Nantz and coworkers [25-27]. Complexes 15 and 18 are chiral, and $\mathbf{1 6}$ is an achiral mesolike compound. Note that $\mathbf{1 7}$ is not a chiral complex as well, as the faces of the ligand are homotopic due to the symmetric position of the bridge with respect to the ligand.

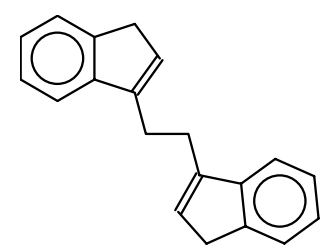

12

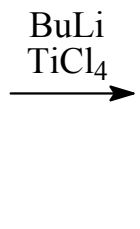

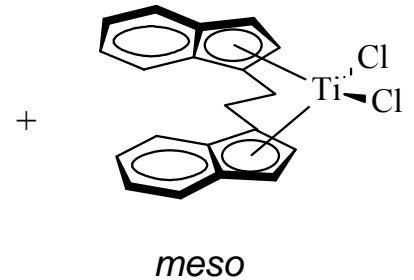

13

\section{Scheme 2}

Compounds 15-18 were obtained by treatment with $\mathrm{TiCl}_{3} \cdot 3 \mathrm{THF}$ with vigorous oxidation of the intermediate by dry air, followed by hydrogenation in presence of $\mathrm{PtO}_{2}$ [25]. In the case of 18, use of $\mathrm{TiCl}_{3} \cdot 3 \mathrm{THF}$ for the metalation of the indene ligand was unsuccessful [27]. Replacing the chloride by $\mathrm{Ti}\left(\mathrm{NMe}_{2}\right)_{4}$ in the synthesis of $\mathbf{1 5}$ resulted in initial metallocene formation, but the product decomposed shortly in the reaction mixture. However, the product was successfully obtained with the use of less than two equivalents of butyllithium. If more than two equivalents were used (as usual for non-bridged titanocenes) the ligand could not be metalated. The possible cause for this effect is metalation of the methylene groups of the bridge forming a dianion incapable of metallocene formation.

Catalytic hydrogenation of the indene products gave pure compounds 15-18. The products can also have substituents in the indene ring, such as $\mathrm{R}=\mathrm{H}, \mathrm{Me} ; \mathrm{R}^{\prime}=\mathrm{H}, \mathrm{i}-\mathrm{Pr}, t-\mathrm{Bu}, \mathrm{Bz}, \mathrm{Ph}, \mathrm{SiMe}_{3}$ in structure 19 [28].

The first phenyl-bridged ligand was prepared by a double Pauson-Khand cyclization, and the corresponding titanocene 20 was obtained by its metalation in $89 \%$ yield [29]. The 4:1 mixture of racand meso-titanocenes was then separated by crystallization from hot toluene.

In order to increase the selectivity of the metalation towards the desired isomer, chirality can be introduced directly in the bridge, either by incorporation of (i) planar chirality or (ii) a chiral center into the bridge. An example of the first case is a (substituted) biphenyl or binaphtyl bridge between two substituted indenyl ligands, which effectively converts the enantiotopic faces into diastereotopic 
faces. At the same time the ligand molecule becomes chiral (planar chirality). For instance, two new chiral ligands were obtained by resolution of the enantiomers of the biphenyl-bridged ligands, followed by the preparation of enantiopure biphenyl-21 (R, R'=H or alkyl) [30].

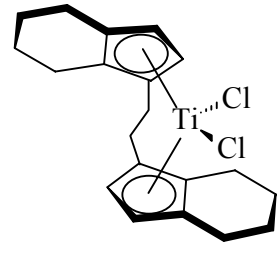

15

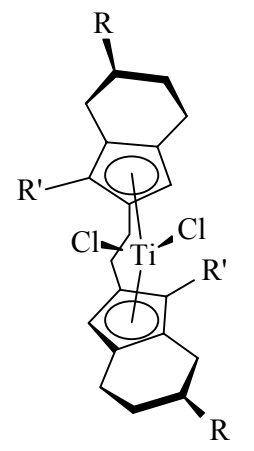

19

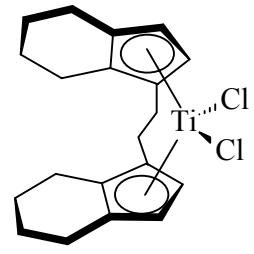

16

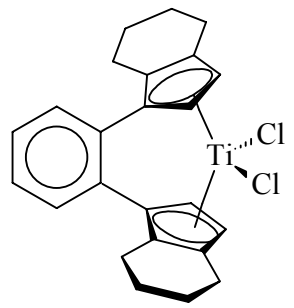

20



17

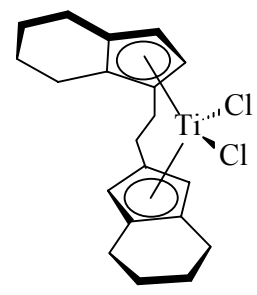

18

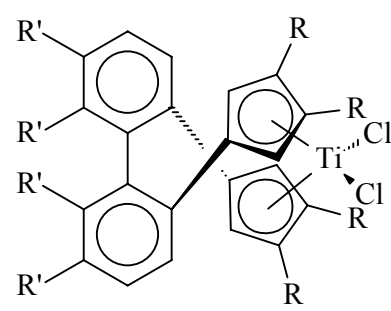

21

The same approach was used for the binaphtyl-bridged titanocenes 22-23 [31,32]. Planar chirality of these complexes is provided by steric hindrance introduced by the two naphtyl groups. The first chiral ligand of this kind, $(R)-(+)-\left(1,1^{\prime}\right.$-binaphtyldyil-2,2'-dimethylene)bis(1-indene), was prepared from (R)-(+)-2,2'-bis(bromomethyl)-1,1'-binaphtyl. Its metalation with $\mathrm{TiCl}_{3}$ gave pure (R)-(-)titanocene 22. Ansa-2,2'-bis[(4,7-dimethyl-inden-1-yl)methyl]-1,1'-binaphtyl titanium dichloride was prepared by reaction of the ligand with $\mathrm{TiCl}_{3}$ followed by oxidation. Only diastereomerically pure $\mathrm{C}_{2}$ symmetrical complexes were obtained, while no diastereomeric $\mathrm{C}_{1}$-symmetrical metallocene was observed.

For its application as hydrogenation catalyst, the bis-indenyl titanocene $\mathbf{2 2}$ has to be converted into the corresponding bis-tetrahydroindenyl compound. Thus, compound 22 was reduced to the tetrahydroindenyl complex by hydrogenation over $\mathrm{PtO}_{2}$ in $\mathrm{CH}_{2} \mathrm{Cl}_{2}$ [33]. However, not only the indene ring may be reduced, but also the unsaturated substituents. It was shown, that when this complex was hydrogenated in the presence of $\mathrm{PtO}_{2}$ in a Parr reactor at $\mathrm{H}_{2}$ pressure of 600 psi, the yield of 23 was $54 \%$ (Scheme 3). If the pressure was increased to $800 \mathrm{psi}$, the naphtyl rings were also hydrogenated into the di-tetralin-bridged titanocene 24 with a yield of $68 \%$ [34]. Preparation of bridged bis(4,5,6,7tetrahydroindenyl) metallocenes by complexing the metal with previously hydrogenated ligands is less favorable due to difficulties in the selective hydrogenation of the benzene ring in the indene. However, preparation of such a complex, 25, from a tetrahydroindenyl silica-bridged ligand was reported [35]. 


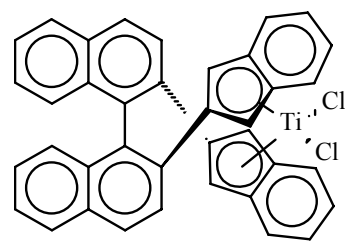

22

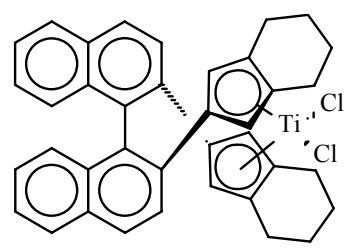

23



24

Scheme 3

Incorporation of a chiral center into the bridge is another strategy for increasing selectivity of the metallation, as illustrated by Chen and Halterman, who synthesized several compounds containing substituents in different positions of the bridge (compound 26) and compounds with an asymmetric cyclic bridge (compounds 27-28) [36,37]. Three enantiomers of $27(\mathrm{R}=\mathrm{H}, \mathrm{i}-\mathrm{Pr}, \mathrm{t}-\mathrm{Bu})$ were successfully separated by crystallization. For the indenyl complex 28, only one enantiomer was obtained, while the appearance of two meso-isomers was not observed. (In contrast, for a similar complex with an ethylene bridge, 15-16, a mixture of rac- and meso-isomers was formed, with ratios ranging from 1:2 to 1:10 [24]). Thus, the cyclic bridge hinders formation of the meso-compound. For the titanocene with propane bridge, 29, only the rac-isomer was obtained [38].

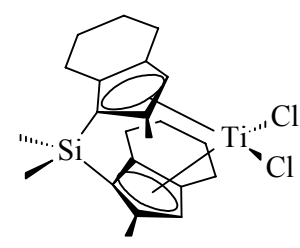

25

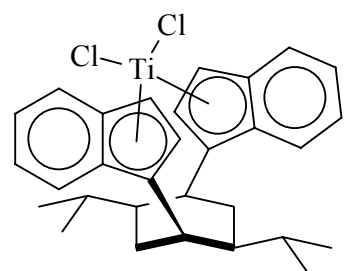

26

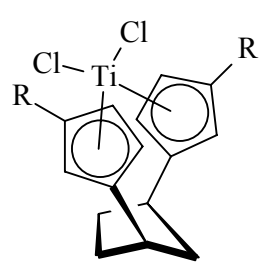

27



28

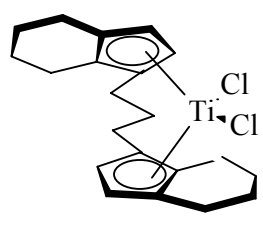

29

Ansa-titanocenes with long-chain bridges can be synthesized by the reduction of alkenylsubstituted unbridged titanocenes [39]. Compounds 30-32 were treated by magnesium, resulting in intramolecular mono- and di-hydrometalation of the ligands by titanium (Scheme 4 [39]). Then, the intermediate complex was decomposed by acidolysis. In all cases, bridged titanocenes were obtained. During the conversion of 30, only the saturated bridge was formed (33). In the case of 32, only titanocene 36 with an unsaturated bridge was obtained, under liberation of gaseous hydrogen. For 31, a mixture of the bridged titanocenes 34 and 35, with saturated and unsaturated bridges in a ratio of 5:2, was formed. Some other examples of carbon-bridged titanocenes with different structure of the bridge were reported in [40-42].

Silicon-bridged ansa-titanocenes, such as 37, can be obtained by metalation of $\mathbf{3 8}$ (Scheme 5) [18, 43-45]. Titanocenes with a silyl bridge, containing vinyl or allyl groups, such as $\mathbf{3 9}(\mathrm{R}=\mathrm{H}$ or $\mathrm{Me})$ were described in [46]. It is worth noting that the incorporation of unsaturated functional groups into the 
bridge makes further modification by hydrosilylation, hydrometalation and anchoring on the surface of solid supports possible.

Due to the flexibility of the mono-bridged ligands, the resulting titanocenes are usually mixtures of $\mathrm{rac} / \mathrm{meso}$ isomers, which have to be separated. This problem may also be resolved by incorporation of a double-bridge in the ligand, to form complexes such as 40-42 [47-49] or disilyl-bridged 43 titanocenes $[50,51]$. Because of the rigid structure of these complexes, only one titanocene enantiomer is obtained.

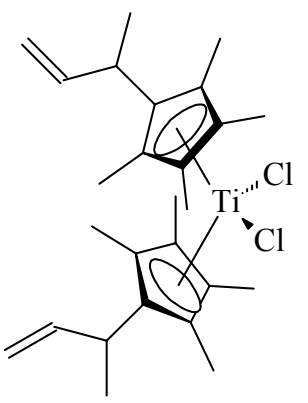

30
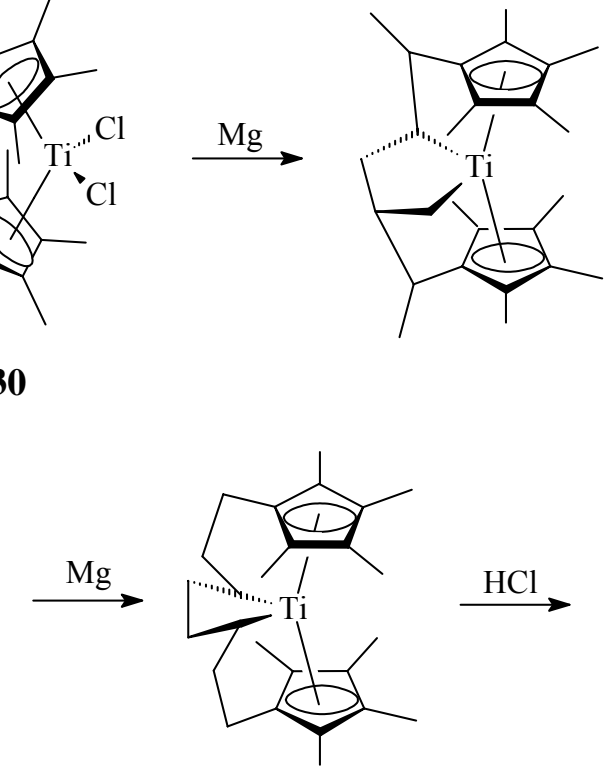

31

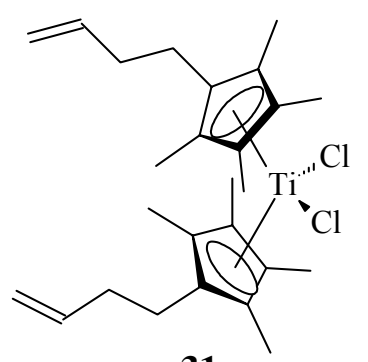

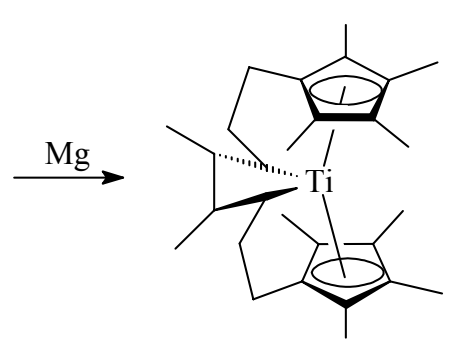

Scheme 4
$\stackrel{\mathrm{HCl}}{\longrightarrow}$

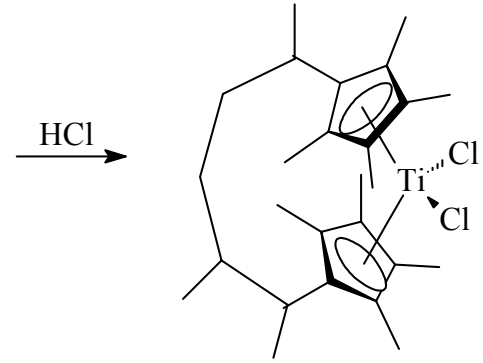

33

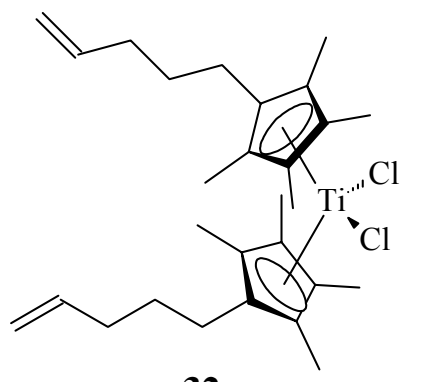

32

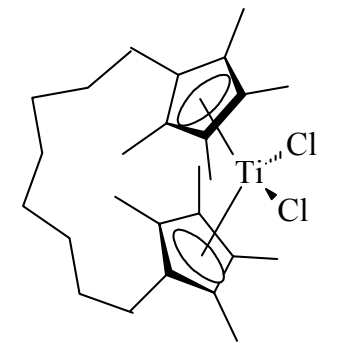

34

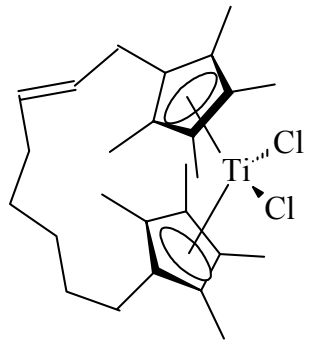

35

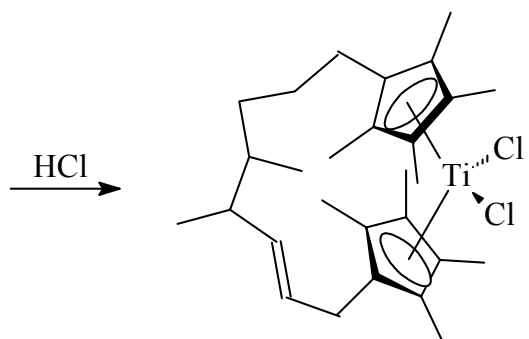

36

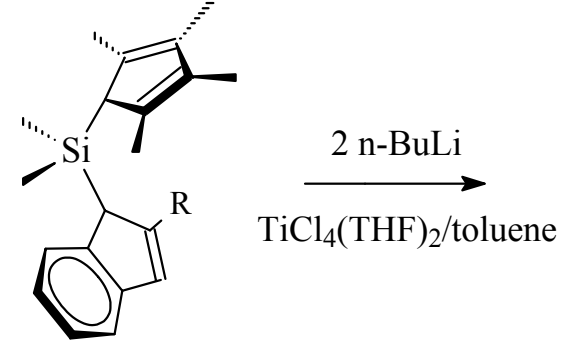

38

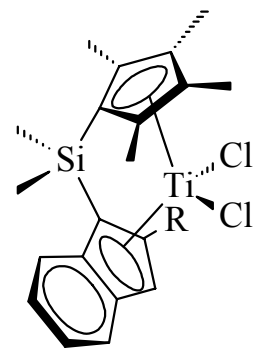

37

Scheme 5 


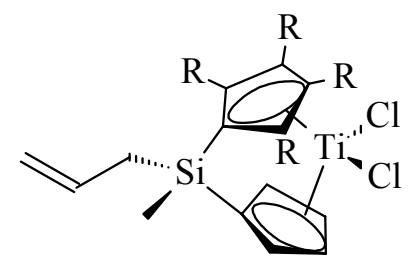

39

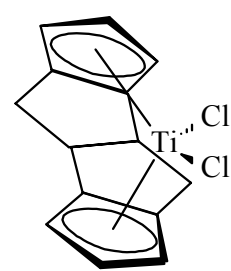

40

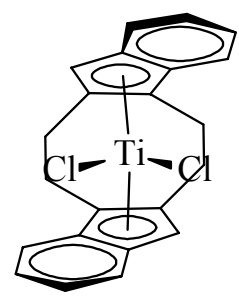

41

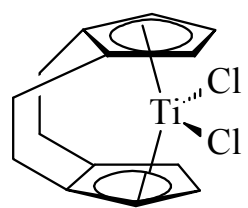

42

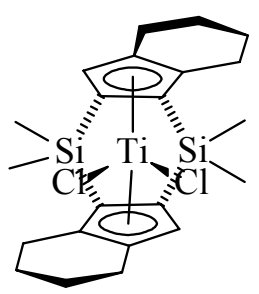

43

\subsection{Active and Enantioselective Form of Titanocene Catalysts}

The catalytically active form of titanocenes are Ti(III) hydride complexes. The first titanocene hydride, $\mathrm{Cp}_{2} \mathrm{TiH}$, was obtained by hydrogenation of $\mathrm{Cp}_{2} \mathrm{Ti}\left(\mathrm{CH}_{3}\right)_{2}$ by Bercaw and Brintzinger [52]. Titanium hydride complexes of this type are extremely unstable in the presence of air. For this reason, titanocene dichlorides are usually reduced in-situ in the reaction mixture with hydrogen, and the active hydride catalyzes the hydrogenation reaction. The disadvantage of this method of catalyst activation is the use of hydrogen under high pressure, which may lead to safety concerns. Instead of hydrogen, phenyl silane can be used. In this approach, titanocene dichloride is treated with butyllithium giving a highly reactive dibutyl derivative, which then reacts with phenyl silane to form the Ti(III) hydride.

For enantioselective hydrogenations, the pure titanocene enantiomer has to be used. However, resolution of the enantiomers is difficult. An effective resolution method is the reaction of the titanocene dichloride with optically pure binaphtol in the presence of sodium excess or lithium binaphtolate. For example, air stable ethylene-1,2-bis $\left(\eta^{5}-4,5,6,7\right.$-tetrahydro-1-indenyl)titanium 1,1'binaphth-2,2'-diolate (44), can be prepared by this method (Scheme 6), which is a useful way for the resolution of the enantiomers of $\mathbf{1 5}$, since the non-racemic binaphtolate reacts with only one titanocene enantiomer and results in formation of only one enantiomer 44 [24]. The other enantiomer of the titanocene dichloride does not react. Purification of the product requires chromatography over activated alumina, and the unreacted enantiomer 15 cannot be recovered. In another method, binaphtol can be used in the presence of triethylamine as a base instead of sodium, and the unreacted enantiomer of 15 can be isolated by precipitation with p-aminobenzoic acid and treatment with conc. $\mathrm{HCl}$ [53]. The active form of the titanocene catalyst, which is the titanium (III) hydride 45, is obtained by treatment of $\mathbf{1 5}$ or $\mathbf{4 4}$ by $\mathrm{BuLi}$ and $\mathrm{PhSiH}_{3}$. When $\mathrm{H}_{2}$ is used, no silane is needed, but $\mathrm{PhSiH}_{3}$ serves to stabilize the active species. Another catalyst precursor is titanocene difluoride (46 is an example), which can be obtained by addition of $\mathrm{NaF}$ to aqueous solution of titanocene dichloride [54]. The precipitated titanocene difluoride can then be filtered and converted to hydride $\mathbf{4 5}$ by direct treatment with $\mathrm{PhSiH}_{3}$ without butyllithium, but other bases (piperidine or pyrrolidine) have to be used.

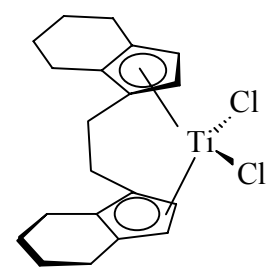

15



Scheme 6

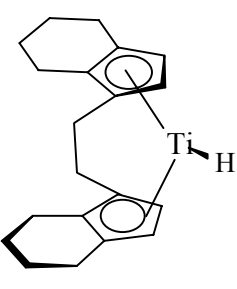

45

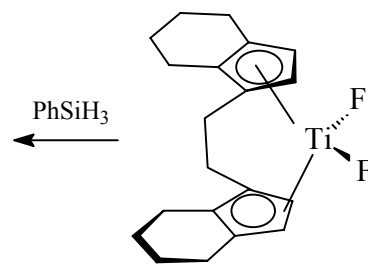

46 


\section{Enantioselective Hydrogenation of Double Bonds}

For over twenty years titanocenes have been used in stereoselective hydrogenations. However, development of new, more active and selective titanocenes is still an area of active research. In this chapter enantioselective hydrogenations and their mechanisms are reviewed.

\subsection{Activity of Titanocenes in Enantioselective Reductions}

Titanocenes are active in the reduction of various types of unsaturated compounds, such as alkenes, imines, ketones and other classes of organic compounds. In this section, stereoselective alkene hydrogenations are discussed first, followed by imine and ketone reductions.

In general, the reduction of double bonds with titanocenes can be carried out with (i) direct hydrogenation or (ii) hydrosilylation, where instead of dissolved dihydrogen silane compounds act as hydrogen donors. A typical procedure for the direct hydrogenation reaction is: to a solution of $\mathbf{4 4}$ (or another catalyst) in THF under argon a solution of $n$-butyllithium is added, followed by addition of phenyl silane or other activation agents. Then, the unsaturated compound, such as an imine or ketone, is added, and the mixture is stirred at $20-65^{\circ} \mathrm{C}$ under $80-2000$ psig $\mathrm{H}_{2}$ for a certain amount of time. The obtained hydrogenated products have a high level of enantiomeric purity [55-58]. For the hydrosilylation, different mono- or di-substituted silanes from a long list can be used, effectively replacing hydrogen. The most widely used silane is PMHS (polymethylhydrosiloxane). After completion of the reaction, the reaction mixture is treated with aqueous $\mathrm{HCl}$, decomposing the silanamine or silyl ether into amine hydrochloride or alcohol, respectively.

\section{Alkenes}

bis(Cyclopentadienyl)titanium dichloride is known to be an active catalyst for alkene hydrogenation for more than forty years [59]. The catalyst is achiral, and the reaction results in the formation of an alkane enantiomer mixture. The first application of chiral titanocenes for the hydrogenation of 2-phenyl-1-butene is relatively recent, in 1981, and was reported by Cesarotti [60]. Chiral menthyl or neomenthyl cyclopentadienyl were the ligands, resulting in moderate enantioselectivity of the hydrogenation.

Further development of chiral olefin reductions was performed by Halterman's group at the University of Oklahoma. Hydrogenation of 2-phenyl-1-butene and 2-ethyl-1-hexene with catalyst 6 resulted in ee's of $64-95 \%$ and $41 \%$, respectively. The catalyst was active at low temperatures (down to $-75^{\circ} \mathrm{C}$ ) [13]. Several bridged chiral ligands were prepared and then metalated with $\mathrm{TiCl}_{3}$ to obtain different chiral titanocene catalysts [61]. As a model reaction the hydrogenation of 2-phenyl-1-butene was carried out in toluene at -20 to $+20^{\circ} \mathrm{C}$. Catalyst $9(\mathrm{R}=\mathrm{H})$ gave products with enantiomeric excesses of $22-34 \%$.

A number of chiral titanocenes were studied for the hydrogenation of 2-phenyl-1-butene and 2-( $\alpha$ naphtyl)-1-butene by Paquette et al. [12]. The hydrogenated products were obtained with ee's between 4 and $69 \%$. The dependence of ee on the size of the substituents at the $\alpha$ position in the ligand (next to the $\mathrm{Cp}$ ring) and syn to the metal atom was established: increase of the size of the substituent (methyl, 
isopropyl, phenyl) are not favorable for high enantioselectivity. For this reaction, the enantioselectivity decreases when one of the chiral ligands was replaced by non-substituted cyclopentadiene.

Silica-bridged titanocenes are also active and selective in alkenes hydrogenation. Comparison of the enantioselectivity of $\mathbf{4 7}$ ( $\mathrm{R}=$ =menthyl or neomenthyl) for the hydrogenation of 2-phenyl-1-butene with other titanocenes showed that only two known titanocenes, 4 and $\mathbf{6}$, gave similar or better ee's [62].

\section{Imines}

Stereoselective imine reductions are important reactions for the production of a wide variety of intermediates in the pharmaceutical and fine chemical industries. Buchwald's group at MIT studied this class of reactions extensively [63-65]. Excellent results were obtained for the hydrogenation of imines with catalyst 44, where ee's between 97-98\% were achieved for cyclic imines [65]. Hydrogenations of acyclic N-benzylimines resulted in lower enantioselectivity (53-85\%) [64]. High hydrogen pressure is required for good enantioselectivity of the hydrogenation of acyclic imines, because the dissolved hydrogen promotes interconversion between anti- and syn-isomers, which have different reaction rates (as shown in section 3.2). In contrast to acyclic imines, the enantioselectivity of cyclic imine hydrogenation is not sensitive to the hydrogen pressure, as there is no anti- and synconversion. Studies of the effect of different functional groups in the cyclic imines showed that the reaction exhibits tolerance towards tri-substituted alkenes, ketones and alcohols, i.e., no reduction of these substituents occurs. However, for imines with terminal $\mathrm{C}=\mathrm{C}$ bonds in the substituent, reduction of all unsaturated bonds occurred, with an ee close to $99 \%$. In general, activity and selectivity of titanocene catalysts for enantioselective imine hydrogenation was higher than for other metal catalysts [64]. It should be noted that imines containing aromatic bromides cannot be hydrogenated due to the reactivity of the catalytically active titanium hydride species with the bromide [66].

Buchwald's group also studied extensively the stereoselective hydrosilylation of imines. Enantioselectivity of the hydrosilylation of most imines was usually very high, i.e., between 92 and 99\% [54]. Only ferrocenyl-substituted imines resulted in somewhat lower ee's of $86 \%$. The reaction also tolerated aromatic chlorides. High enantioselectivity was observed during the imine hydrosilylation with $\mathbf{4 6}$, due to its easier conversion into the hydride intermediate. For example, S,S-46 catalyzed the reaction of N-benzyl-1-indanimine in the presence of PMHS as a hydride donor and isobutylamine as a promoter to give (+)-N-benzyl-1-indanamine with $95 \%$ yield and $92 \%$ ee $[54,67]$.

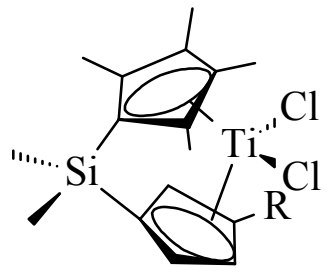

47

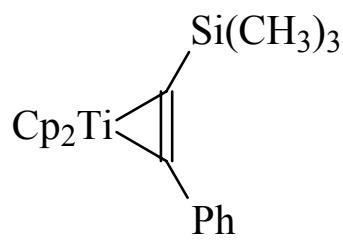

48

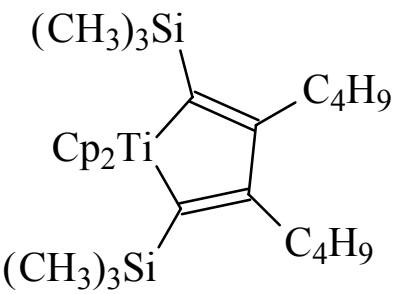

49

Tillack et al. [68] studied the hydrosilylation of aldimines and ketimines by $\mathrm{Ph}_{2} \mathrm{SiH}_{2}$ in the presence of different titanocene complexes containing two different additional ligands linked to the $\mathrm{Ti}$ atom by Ti-C $\sigma$-bonds (in addition to the $\mathrm{Cp}_{2}$-derivates). It was found that two factors affect the 
conversion: the substituent at the nitrogen in the substrate and the leaving group (ligand) bound to the titanium atom. The nature of the substituent in the imine determines its steric properties, while the rate of formation of the catalytically active titanium hydride depends on the nature of the leaving group. For example, titanocene $\mathbf{4 8}$ appeared the most active, while the activity of $\mathbf{4 9}$ was very low.

Titanocene catalyst $\mathbf{4 4}$ was also successfully utilized for the kinetic resolution of racemic disubstituted 1-pyrrolines via enantioselective hydrogenation [69]. The reaction continued until 50\% conversion of the initial racemic pyrroline was reached. For example, it was found that after hydrogenation of $( \pm)$-3-benzyl-2-phenyl-1-pyrroline the reaction mixture contained mainly the unreacted $R-(+)$-pyrroline enantiomer and the product, 2R,5S-(-)-pyrrolidine. Similar results were obtained for other pyrrolines. Another example of efficient separation is the kinetic resolution of $\mathrm{N}$ alkyl imines, 3-substituted indanones, and 4-substituted tetralones via hydrosilylation using a chiral catalyst [70]. After hydrosilylation of the racemic mixture of the imine enantiomers $50(\mathrm{R}=\mathrm{Me}, \mathrm{Ph}, n$ $\mathrm{Bu}, t-\mathrm{Bu})$, followed by hydrolysis of the unreacted imine, $(R)$-indanones 52 were recovered with ee's between 71 and $94 \%$, while the (S)-enantiomer was converted to the correspondent amines 51 (Scheme 7).

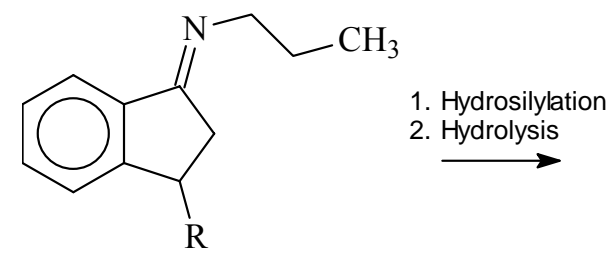

50

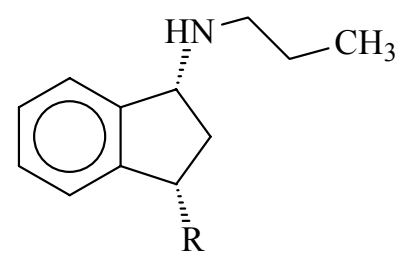

51

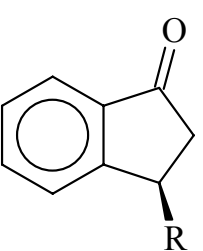

52

\section{Scheme 7}

\section{Ketones}

Catalytic chiral hydrosilylations of ketones were first reported in 1971 [71] and have been extensively studied since. However, no general hydrosilylation method was developed until the end of the last century. Recently several papers outlining a general method for the enantioselective synthesis of chiral alcohols were published. Halterman's group studied the catalytic complexes 6, 23 and 26 in the asymmetric hydrosilylation of aryl alkyl ketones [72]. The reactions were carried out by treatment of the complexes with $n$-BuLi, followed by addition of triethoxysilane and the ketone at $-78^{\circ} \mathrm{C}$. However, the ee's of the reaction appeared to be low. The highest selectivity (40\%) was observed for 2-acetylnaphtalene, while (4-methylphenyl)methylketone showed no apparent selectivity towards one enantiomer. It was found that the introduction of a $p$-methyl or $p$-methoxy group to the phenyl ring greatly reduced enantioselectivity, while a $p$-bromo group gave a significant increase. Better results for the hydrosilylation of aromatic ketones were obtained by Buchwald's group [73]. Catalyst activation and reaction were carried out with PMHS. The reaction proceeded at room temperature for several days, and the highest ee's were observed for acetophenone and 2-acetylnaphtalene (97 and 95\%, respectively). Reduction of ortho- and para-substituted aromatic ketones, except for p-(trifluoromethyl)acetophenone, displayed good enantioselectivity, while it was poor for ketones without an unsaturated bond at the $\alpha$-position to the chiral center. 
Hydrosilylation of prochiral ketones with different hydrosilanes was studied by Rahimian and Harrod [74]. The catalysts, $\mathrm{Cp}_{2} \mathrm{TiMe}_{2}, S, S-(\mathrm{EBTHI}) \mathrm{TiMe}_{2}$ and (S,S,S)-(EBTHI)Ti(binaphtolate) (EBTHI=ethylenebis(tetrahydroindenyl)) were pre-treated with $\mathrm{MeLi}$ or $\mathrm{BuLi}$ and different hydrosilanes, such as $(\mathrm{EtO})_{3} \mathrm{SiH}, \mathrm{Me}(\mathrm{EtO})_{2} \mathrm{SiH},[\mathrm{MeSi}(\mathrm{H}) \mathrm{O}]_{4}, \mathrm{Me}_{3} \mathrm{SiO}[\mathrm{MeSi}(\mathrm{H}) \mathrm{O}]_{\mathrm{n}} \mathrm{SiMe}_{3}$ and $\mathrm{MeSiH}_{3}$. In all cases, the catalyst pretreatment with BuLi gave better ee's. For example, for the hydrosilylation of acetophenone, the ee was $>99 \%$, while pre-treatment with MeLi resulted in an ee of only $17 \%$. In general, the ee's found using titanocenes were higher than that using other titanium complexes, such as chiral binaphtol-titanium complexes [75].

A new chiral complex 47 ( $\mathrm{R}=$ menthyl or neomenthyl) was tested for the hydrosilylation of acetophenone by White and coworkers $[62,76]$. This complex was prepared as a mixture of two isomers: $R$ and $S$, from which the $R$-titanocene was isolated by crystallization from the reaction mixture, while the $S$-isomer was separated only after isomerization of the racemic mixture under UV irradiation. Both isomers showed activity for the hydrosilylation of ketones. However, their enantioselectivity appeared different. While $(S)-\mathrm{PhCH}(\mathrm{Me}) \mathrm{OH}$ was obtained with the $(R)$-titanocene at an ee of $82 \%$, the $(S)$-titanocene resulted in only $16 \%$ ee of the $(R)-\mathrm{PhCH}(\mathrm{Me}) \mathrm{OH}[76]$. In a later study of this group, a range of ketones was tested for the hydrosilylation using the same catalyst [62]. In all experiments, the $R$-isomer of the catalyst showed higher enantioselectivity than the $S$-isomer. This effect is due to the orientation of the menthyl group: the isopropyl group of the menthyl substituent points across the face of the $R$-catalyst, while in the $S$-catalyst it points toward the back side of the complex, and the catalyst face is occupied by a proton. In addition, the presence of electron-donating groups in the aromatic ring of the substrate improved both the rate and enantioselectivity of the reaction. This effect is caused by the interaction between the highly electropositive Ti center and the electron-rich aromatic ring, resulting in a more rigid transition state. In contrast to imine hydrosilylations, the hydrosilylation of ketones tolerates aromatic bromides [73].

Several additional examples of enantioselective reductions of unsaturated compounds are presented in Table 1.

Table 1. Some examples of enantioselective reductions with chiral titanocenes.

\begin{tabular}{|c|c|c|c|c|c|c|c|c|c|}
\hline Substrate & $\begin{array}{c}\text { Conv. } \\
\% \\
\end{array}$ & $\begin{array}{c}\text { TOF, } \\
\text { 1/h }\end{array}$ & $\begin{array}{l}\text { ee, } \\
\%\end{array}$ & Ref. & Substrate & $\begin{array}{c}\text { Conv. } \\
\% \\
\end{array}$ & $\begin{array}{c}\text { TOF, } \\
\text { 1/h } \\
\end{array}$ & $\begin{array}{l}\text { ee, } \\
\%\end{array}$ & Ref. \\
\hline & 80 & 2.0 & 99 & 65 & & & & & \\
\hline & $96^{\mathrm{a}}$ & 80 & 98 & 54 & & $72^{\mathrm{d}}$ & 0.63 & 99 & 65 \\
\hline & $100^{\mathrm{b}}$ & 2.08 & 60 & 62 & & & & & \\
\hline & 78 & 0.65 & 98 & 65 & & 84 & 0.26 & 95 & 73 \\
\hline & 73 & 0.75 & 97 & 73 & & 92 & 0.22 & 91 & 73 \\
\hline & 34 & 0.23 & 99 & 69 & & $86^{\mathrm{a}}$ & 10.75 & 99 & 82 \\
\hline
\end{tabular}


Table 1. Cont.

\begin{tabular}{|c|c|c|c|c|c|c|c|c|c|}
\hline Substrate & $\begin{array}{c}\text { Conv. } \\
\%\end{array}$ & $\begin{array}{c}\text { TOF, } \\
\text { 1/h }\end{array}$ & $\begin{array}{l}\text { ee, } \\
\%\end{array}$ & Ref. & Substrate & $\begin{array}{c}\text { Conv. } \\
\% \\
\end{array}$ & $\begin{array}{c}\text { TOF, } \\
\text { 1/h }\end{array}$ & $\begin{array}{l}\text { ee, } \\
\%\end{array}$ & Ref. \\
\hline$-\mathrm{C}_{2} \mathrm{H}_{5}$ & 78 & 0.65 & 94 & 66 & & $80^{\mathrm{a}}$ & 8.0 & 98 & 82 \\
\hline & 85 & 0.38 & 92 & 64 & & 100 & 1.85 & 50 & 74 \\
\hline $\mathrm{CH}_{3}$ & $95^{\mathrm{a}}$ & 395.8 & 99 & 54 & & 79 & 0.32 & 95 & 65 \\
\hline & $72^{\mathrm{f}}$ & 0.6 & 95 & 66 & & 79 & 0.33 & 95 & 77 \\
\hline & 94 & 2.09 & 99 & 77 & & 87 & 0.05 & 83 & 77 \\
\hline & 75 & 0.62 & 92 & 66 & & $79^{\mathrm{e}}$ & 0.69 & 99 & 65 \\
\hline & $100^{c}$ & 1.04 & 61 & 12 & & $96^{\mathrm{a}}$ & 38.4 & 92 & 81 \\
\hline
\end{tabular}

The catalyst used was $\mathbf{4 4}$ except where noted. ${ }^{a}$ Catalyst $\mathbf{4 6} .{ }^{\mathrm{b}}$ Catalyst $\mathbf{4 7}\left(\mathrm{R}=\right.$ menthyl). ${ }^{\mathrm{c}}$ Catalyst $4 .{ }^{\mathrm{d}}$ Converted into 2-hexylpyrrolidine. ${ }^{\mathrm{e}}$ Converted into 2-(4-methyl-3-pentenyl)-pyrrolidine. ${ }^{\mathrm{f}}$ Converted into 1-[1-(1-cyclohexen-1-yl)ethyl]-pyrrolidine.

\subsection{Reaction Mechanisms}

\section{Hydrogenation}

The mechanism of enantioselective reductions of alkenes via a chiral titanocenes is illustrated in Scheme 8 [77]. The olefin approaches from the (open) front of the titanocene hydride to form a $\eta^{2}$ complex with the active site (titanium hydride). The monosubstituted olefinic carbon atom bonds to the Ti(III) atom, while the hydride is transferred to the disubstituted olefinic atom (four-center transition state). The steric arrangement in this case is more favorable for the formation of the transition complex, because the bulky substituents at the tertiary carbon atom are located in the position with less steric hindrances [77]. Due to the more crowded transition states in the case of the Zalkenes (both faces lead to steric interaction), their rate of hydrogenation is slower than it is for $E$ alkenes. For the E-olefin, the transition state $\mathbf{A}$ will give a certain enantiomer and transition state $\mathbf{B}$ gives the opposite enantiomer. However, the transition state of $\mathbf{A}$ is less crowed and therefore, high 
ee's can be expected. In the case of the Z-olefin, both transitions states are crowed, and it depends on the relative size of the substituents. Although it is not obvious from Scheme 8, the interaction between the group at the secondary carbon and the indenyl ligand ( $\mathbf{B}$ and $\mathbf{D})$ is more important than the one between $\mathrm{R}_{\mathrm{L}}$ and the ligand (B and $\mathbf{C}$ ). Thus, if the group at the secondary carbon has the same bulk as $\mathrm{R}_{\mathrm{L}}$, transition state $\mathrm{C}$ should be favored over $\mathrm{D}$. In the opposite case (i.e., $\mathrm{R}_{\mathrm{L}}$ is significantly larger), the other transition state will be favored. However, since in both cases (C and $\mathbf{D})$ there appears steric interaction, the ee's may not be as high, and the overall reaction rates may be lower. Thus, the orientation of the substituent at the less substituted carbon atom (i.e., E or Z) controls the stereoselectivity of the product. In support of this suggestion, experimental data showed that the highest ee (>99\%) was observed for the hydrogenation of 1-methyl-1,2-diphenylethylene E-isomer, where one carbon atoms has two large substituents, and one has one small substituent [77]. The rate of this reaction is sensitive to the sterics of the substrate. Thus, high pressures and temperatures are necessary for hydrogenation of alkenes with bulky substituents at double bond, as the transition state are energetically unfavorable.

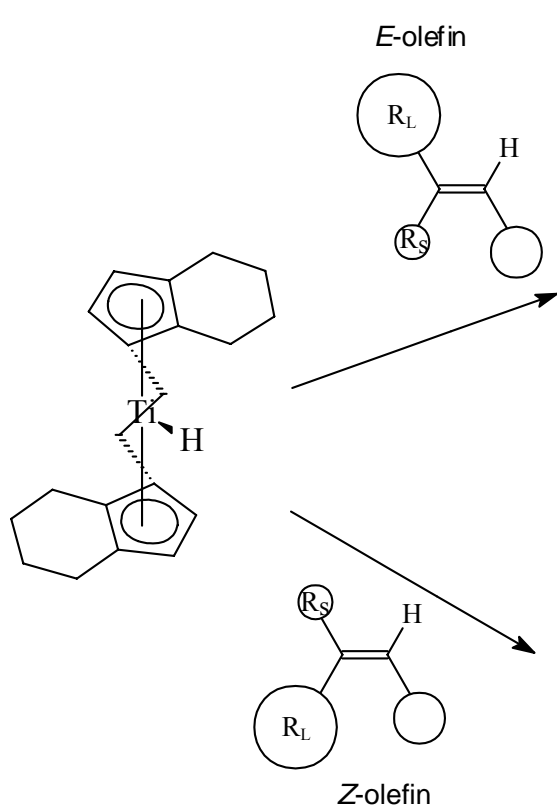

Z-olefin

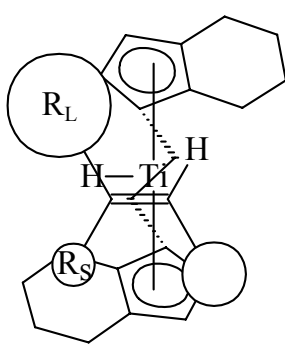

A

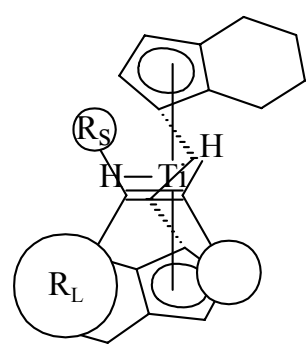

$\mathrm{C}$

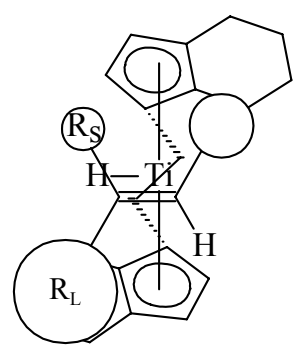

$\mathrm{B}$

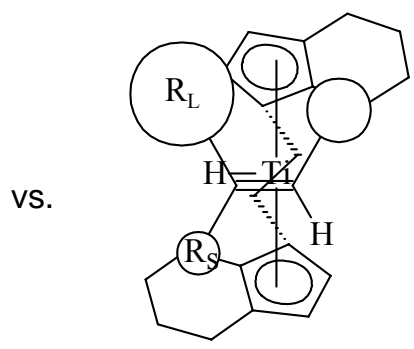

$\mathrm{D}$

\section{Scheme 8}

The mechanism of imine hydrogenation with an $(R, R)$ catalyst is shown in Scheme 9 [63]. In the case of acyclic imines, rapid isomerization occurs, thus leading to a mixture of the syn- and antiisomers. In the first step, the titanium hydride reacts with both unsaturated isomers, forming two diastereomeric titanium amide complexes. Hydrogenolysis of these intermediates via $\sigma$-bond metathesis regenerates the titanium hydride and forms the $R$ - and $S$-enantiomers. In order to explain the stereochemistry of the reactions and the effect of isomerization, Willoughby and Buchwald [78] proposed a mechanism for the hydrogenation of acyclic imines illustrated in Scheme 10. The proposed mechanism suggests fast insertion of the imines into the titanocene hydride with formation of an intermediate titanium amide.

Depending on the isomers (syn-, anti-) of the imine and the arrangement of the transition state (i.e., $R, R, S$ or $R, R, R$ ) the reaction has different rates. As shown before for the case of olefin hydrogenation, 
one of the anti-isomer transition states leads to less steric hindrance compared to all the other transition states. In general, the various outcome of the different reaction pathways of the transition state formation are equivalent to olefin reduction. However, in contrast to what would be expected, authors showed that the syn-isomer is the more reactive one (it is not clear, which step is responsible for this difference: insertion of the imine or hydrogenolysis of the intermediate). The chiral imine insertion is then followed by slow hydrogenolysis to the amine or slow $\beta-\mathrm{H}$ elimination of the imine to revert to the starting compound. Interconversion between the anti- and syn-isomers occurs as well and was shown to be independent of the hydrogen pressure. However, the hydrogen pressure affects the rate of hydrogenolysis to the product, which explains the strong effect of the hydrogen pressure on the ee. Isomerization of the double bonds to form chiral imines is slow and has no impact on the selectivity of this reaction.

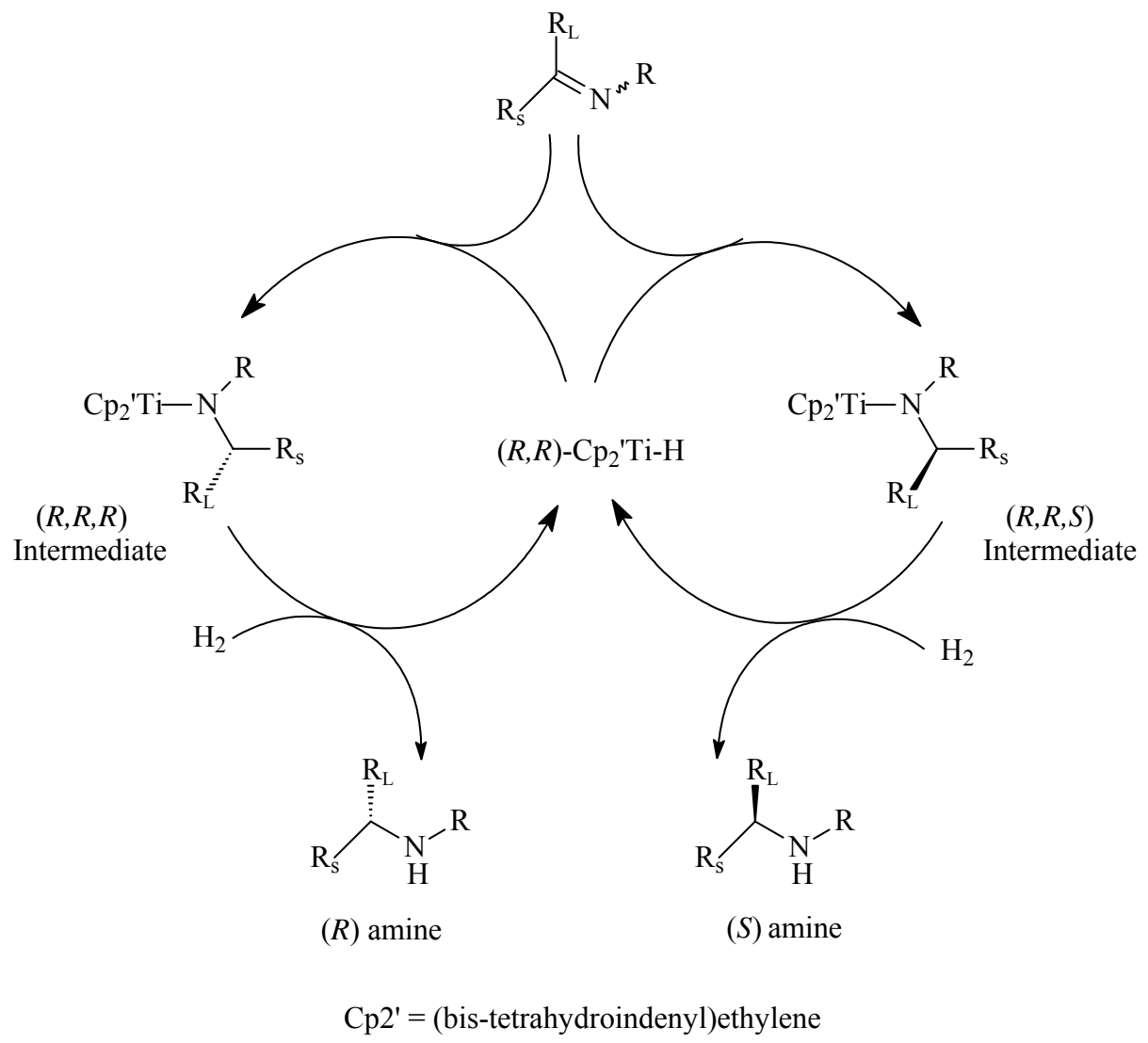

Scheme 9

Enantioselectivity of this reaction depends mainly on the group at N-atom $\left(R_{N}\right)$ rather than those on the $\mathrm{C}$-atom $\left(\mathrm{R}_{\mathrm{L}}\right.$ and $\mathrm{R}_{\mathrm{S}}$ ), as $\mathrm{R}_{\mathrm{N}}$ is closer to the catalyst center, while $\mathrm{R}_{\mathrm{L}}$ and $\mathrm{R}_{\mathrm{S}}$ lead to less steric interactions.

The high reactivity of cyclic imines can also be explained by steric factor. The rate-limiting step of the hydrogenation is hydrogenolysis of the Ti-N bond in the intermediate titanium amide. For cyclic imines, both N-substituents in the transition state complex are "tied back" (pointing away from the metal center), providing high reactivity of the titanium amide with hydrogen, which can easily reach the reactive center. Also, there is no trans-cis-isomerization resulting in the conversion of highly reactive isomer into less reactive ones. 


\section{Hydrosilylation}

Hydrosilylations of alkenes [79] or alkynes [80] on titanocene catalysts are known in the literature. However, in contrast to Si-N or Si-O bonds, the Si-C bond is stable under hydrolyzing conditions. For this reason, hydrosilylation of alkenes is not considered a method for chiral alkane synthesis.

In the hydrosilylation of imines, the transition amido-titanium complex is formed by insertion of the imine into the titanium-hydrogen bond, similar to the insertion during hydrogenation. Then, the catalytic complex reacts with phenylsilane (Scheme 11) or other silylating agents to form a four-center transition state. Subsequent $\sigma$-bond metathesis results in the formation of the silylated amine and the regeneration of the titanocene hydride [54]. After hydrolysis in acidic media, silylamine decomposes into the amine hydrochloride. The absolute configuration of the enantiomers obtained during this reaction is the same as for the hydrogenation.

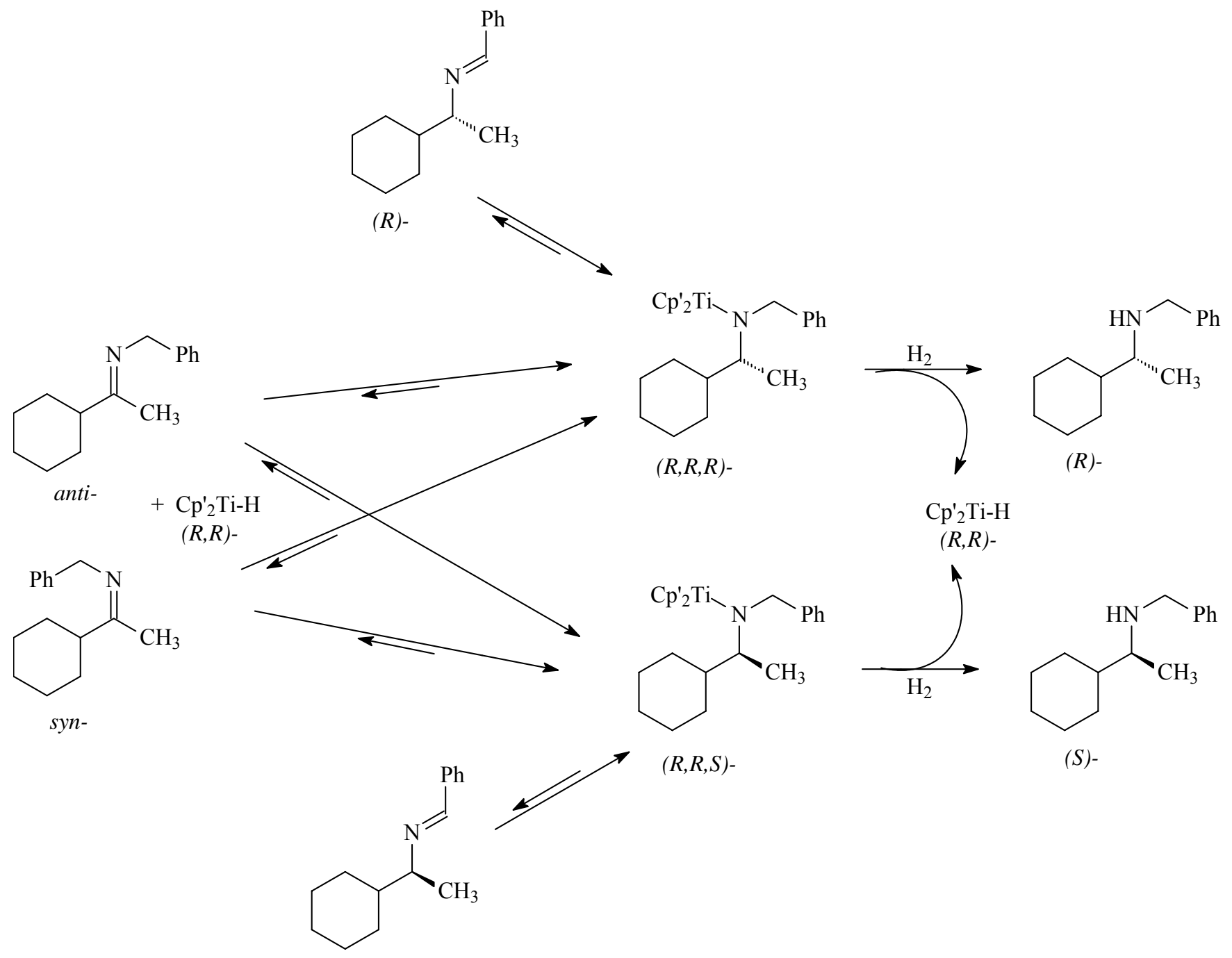

(S)-

Scheme 10 


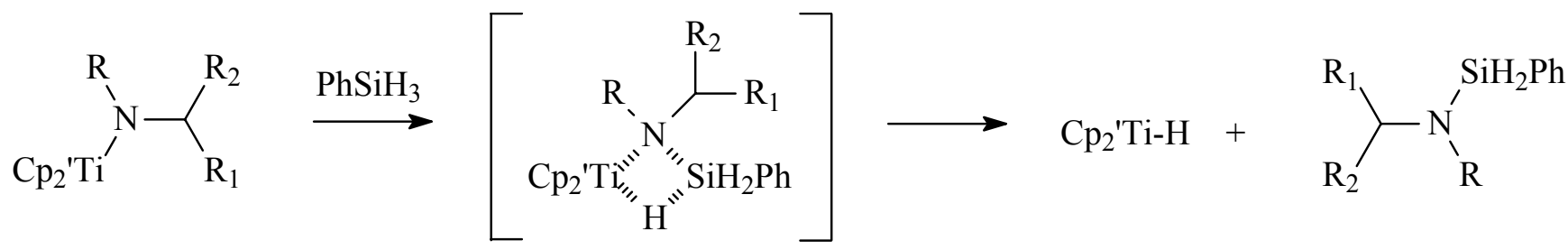

Scheme 11

Two suggested mechanisms for the ketone hydrosilylation are compatible with experimental data [74]. The first mechanism involves a Ti(III) hydride intermediate (Scheme 12). In accordance with this mechanism, the titanocene hydride serves as a precursor to the intermediate silyl complex. The ketone inserts into the Ti-Si bond of this complex. Then, the resulting ligand is displaced by silane to generate the product and regenerate the silylated titanocene. The strong effect of the nature of the silane on the reaction rate and the ee's is explained by a higher reactivity of a small silyl ligand at the titanium atom. The second mechanism involves hydrosilyl titanium (IV) intermediates where the silyl ligand exerts its influence on the reaction rate and ee's (Scheme 13). In this case, the ketone inserts into Ti-H bond, followed by metathesis with the silane to generate the product and regenerate the silylated titanocene hydride.

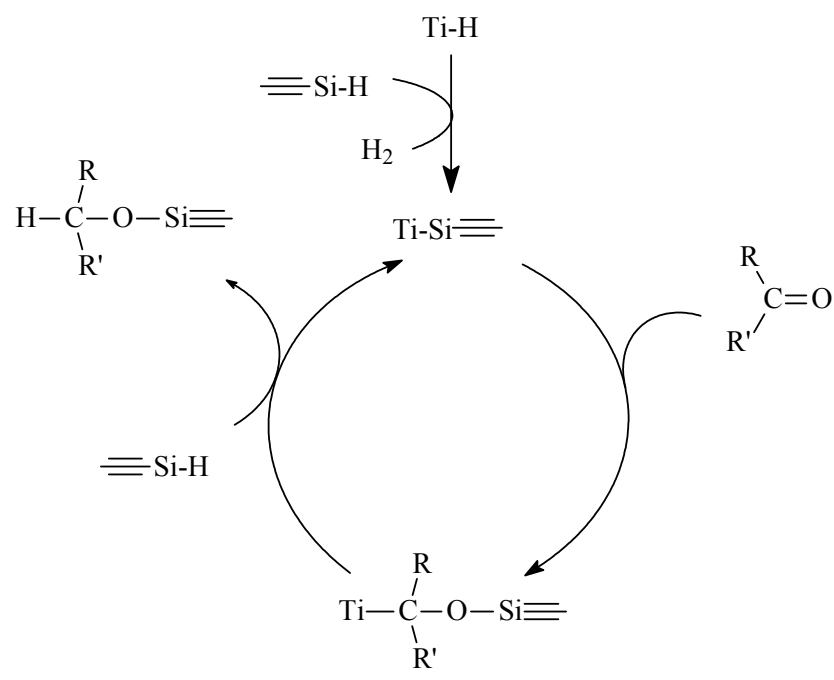

Scheme 12

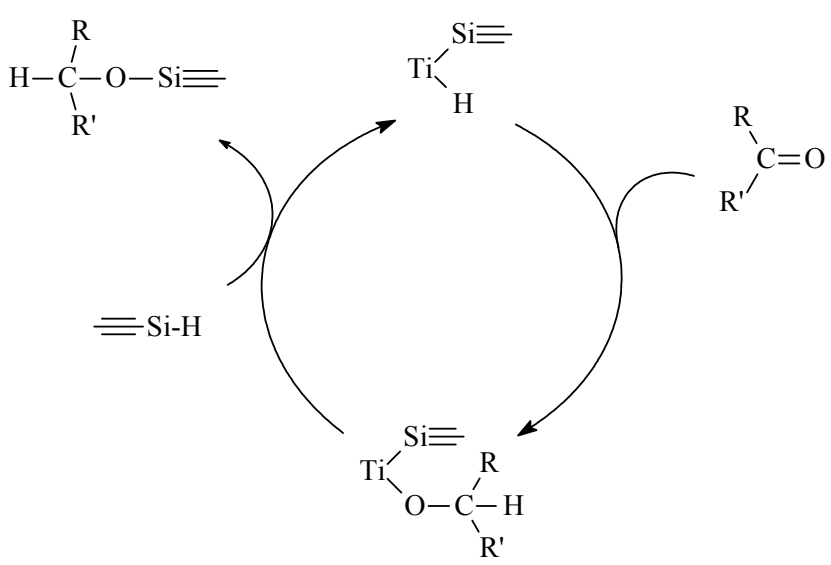

Scheme 13

It is not clear as of yet, which of the two (or both) mechanisms is the one occurring. Enantioselectivity and stereo-control of this reaction were discussed by Buchwald and co-workers [73]. In contrast to imine and olefin reductions, where the stereo-control is mainly exerted by the substituent on the nitrogen or secondary carbon, the stereochemistry of ketone reductions is only controlled by the two substituents on the prochiral carbon. The transition state model for this reaction, where one substituent is an aryl and the other an alkyl substituent $\mathrm{R}$ ( $\mathrm{R}=$ methyl, isobutyl, cyclohexyl, etc.), is shown in Scheme 14. Under the assumption that the aryl group remains in conjunction with the carbonyl group throughout the reaction, the aryl group is forced into close contact with the cyclohexyl ring of the titanocene ligand in the transition state $\mathbf{A}$, while this steric interaction is nominal in the transition state $\mathbf{B}$, as the alkyl group is free to rotate. In this case, i.e., for conjugated ketones, the 
observed enantioselectivity is high. For unconjugated ketones, however, rotation of the side chain can $\underset{\text { occur, which minimizes steric interactions and therefore results in poor enantioselectivity. }}{\text { Side View }}$

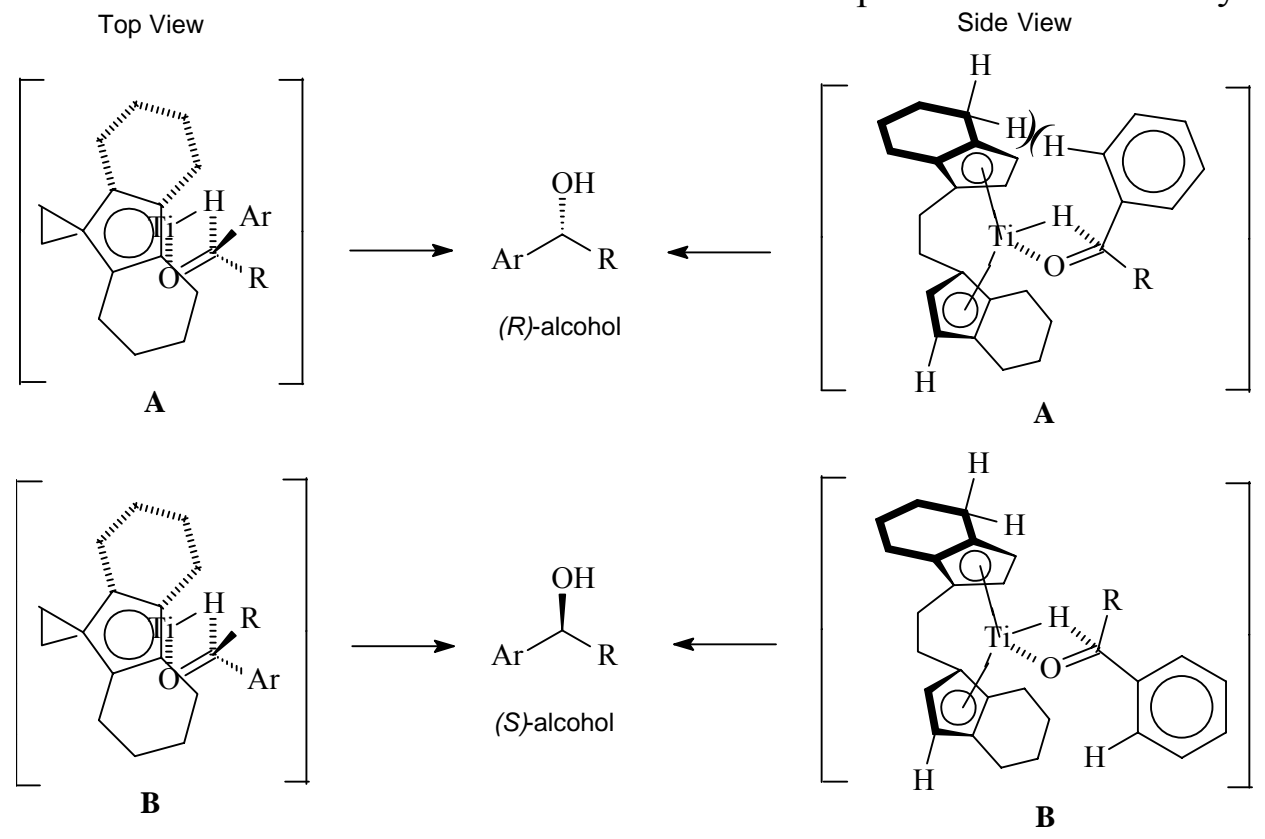

\section{Scheme 14}

The effect of large substituents in the ligand on the enantioselectivity of ketone hydrogenations is illustrated in Scheme 15 [62]. The boxes represent the reactive centers, and the positions of the silyl bridge, the two $\mathrm{Cp}$ ligands and the menthyl group are shown with respect to the reactive center (box). The ketone can approach the titanium atom mainly from the opposite side of the menthyl group. Thus, the orientation of the bulky menthyl group in the ligand causes a difference between the enantioselectivity of the (R)- and (S)-isomers. For example, hydrosilylation of $\alpha$-tetralone on $(R)-47$ resulted in $43 \%$ of $(S)$ - $\alpha$-tetralol, while the ee of $(R)$ - $\alpha$-tetralol on $(S)-47$ was only $10 \%$.

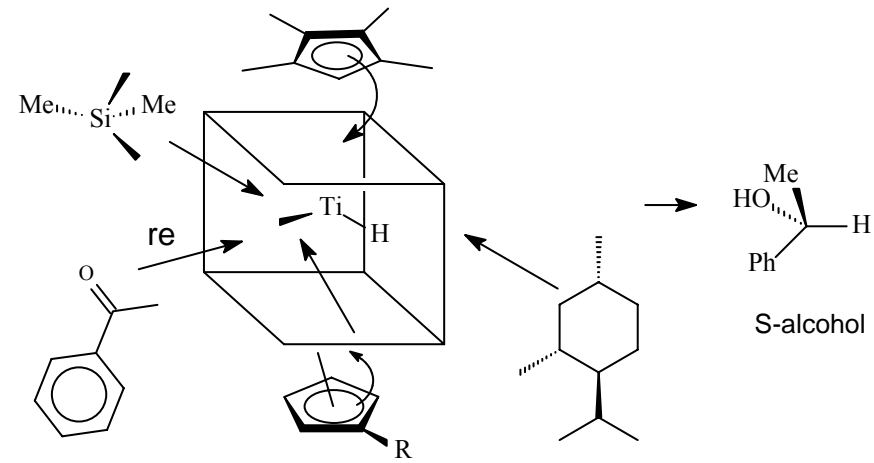

R-complex

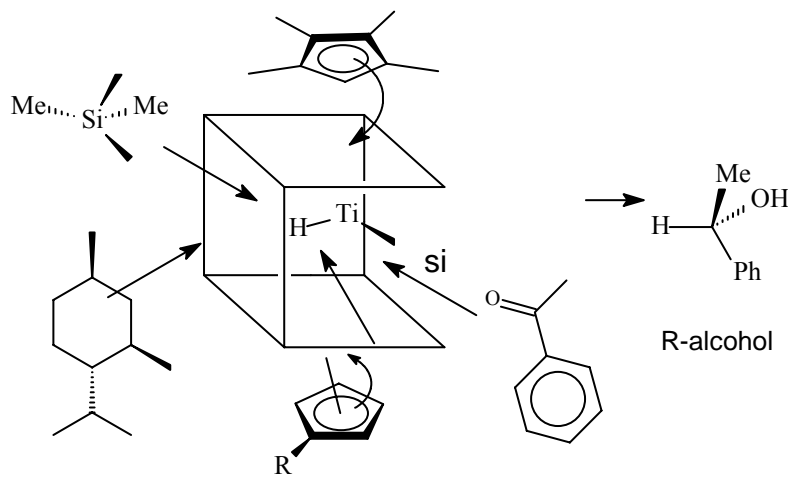

S-complex

Scheme 15

Other factors affecting the enantioselectivity are the kinetics of complexation and the rate of hydrogen transfer. 


\subsection{Effect of Additives and Solvents}

The hydrosilylation of imines is promoted by a slow addition of amines, which transform the transition complex into a more reactive species. The suggested mechanism of the amine-promoted catalysis includes reaction of the added amine with the titanocene intermediate complex with replacement of the hydrogenating substrate (Scheme 16) [81]. During the first step, the titanocene hydride forms an intermediate complex with the prochiral imine. The amine additive then reacts with this complex to release the chiral amine and to generate another intermediate complex, which is less hindered. During the last step, the complex reacts with silane regenerating the titanocene hydride.

Addition of amines to the reaction mixture increased both conversion and enantioselectivity of the hydrosilylation reaction. Use of isobutylamine as promoter allows replacement of phenylsilane by polymethylhydrosiloxane, which is less expensive (but also less active without presence of amine). Interestingly, it was found that the enantioselectivity of the products does not correspond to the E: $Z$ ratio of starting imines, but appears to be higher. The source of the non-linearity of this transformation is still unclear. However, the authors suggest the involvement of enamine intermediates [81].

As the imine hydrosilylation is promoted by amine addition, in analogy ketone hydrosilylation is promoted by alcohol addition. In this case, displacement of the chiral alcohol from the Ti atom by a less hindered alcohol enhances the rate of hydrogenation. Yun and Buchwald [82] found that addition of primary alcohols, $\mathrm{C}_{1}-\mathrm{C}_{4}$, to the reaction mixture improved the ee's and the reaction rate. The suggested mechanism is similar to that of the imine hydrosilylation. However, there are differences. In both cases, the steps determining rate and enantioselectivity are different: the first is $\sigma$-bond metathesis in the four-centered transition complex, and depends on the additive. The second step is the addition of the ketone to the titanium hydride, which is not influenced by the additives in the case of ketone reductions. However, small ee effects are caused by the increase of the asymmetric hydrosilylation rate, whereas nonselective reduction pathways are minimized.

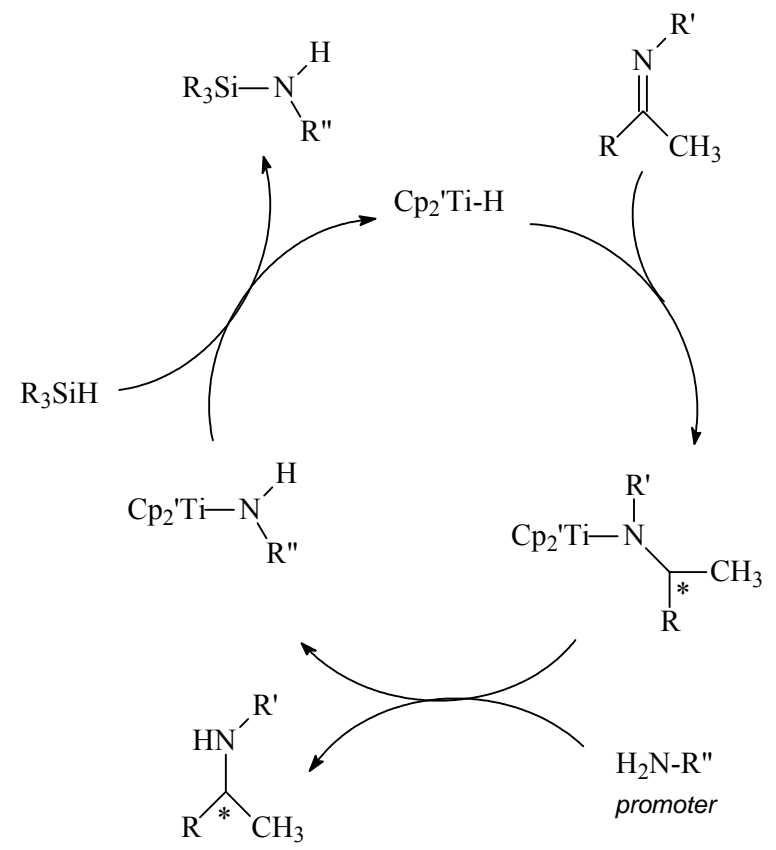


Only a few studies address solvent effects in chiral hydrogenations, and this is still an open area of research. Stereoselective reductions using chiral titanocenes are typically carried out in aprotic, polar and nonpolar solvents, such as THF, benzene, hexane, toluene and others. For example, the activity of the catalyst for 1,1-disubstituted alkene hydrogenation in hexane was found to be significantly higher than in toluene [12]. No further explanations were provided, but possibly the $\pi$-coordination of toluene to the titanium center hinders the reaction.

Some solvent effects were found for the hydrogenation of acyclic imines. For all $\mathrm{H}_{2}$ pressures the use of THF resulted in slightly lower ee's than benzene. In contrast to acyclic imines, no solvent effects were found for cyclic imines [78], suggesting that the solvent has an influence on the rate of the E-Z isomerization.

A study of the solvent effects in ketone hydrosilylations [62] showed that use of THF is favorable for the hydrosilylation rate, but dramatically decreased the ee's, which was explained by the coordinating ability of THF to the catalyst. The highest ee's were obtained with toluene as a solvent. Unexpectedly, it was found that traces of water are favorable for enantioselectivity of ketone hydrosilylation but the conversion of ketones decreases.

\subsection{Kinetic Studies}

Only a few studies on the kinetics of chiral hydrogenations have been carried in the past. Almost all of these studies addressed imine reductions. In Table 1, the TOFs of selected reactions are reported, which were computed using the initial and final substrate concentration based on the elapsed time period. Thus, the reported TOFs are averaged data, and do not represent initial TOFs. However, from Table 1 it can be seen that a lot remains to be desired. In the past high TOFs have been reported (up to $300 \mathrm{~s}^{-1}$ ) for (non-chiral) terminal olefin reductions with $\mathrm{Cp}_{2}$-type titanocenes [83]. Thus, there is room for improvement, i.e., by optimization of the reaction conditions. However, up to date no investigations have been carried out in this direction.

A kinetic study of imine hydrogenations by Buchwald [78] showed that the reaction rate is independent of the cyclic imine concentration, but depends on the catalyst concentration and hydrogen pressure, i.e., the rate $=\mathrm{k}[\mathrm{Ti}]\left[\mathrm{H}_{2}\right]$. These data are in good agreement with the suggested mechanism (discussed above), which involves (1) fast insertion of imine into the titanocene hydride, (2) slow $\beta-\mathrm{H}$ elimination of imine from the transition complex, and (3) slow hydrogenolysis of the transition complex to form amine. For acyclic imines, the order of the reaction in hydrogen is different (for example, 1 for ketimine 53, and 0.6 for aldimine 54). Moreover, during hydrogenation of acyclic ketimines, formation of aldimines is observed during hydrogenation. Thus, during the hydrogenation of imine 53 to amine 55, a small amount of aldimine 54 (intermediate) appears in the reaction mixture and begins to disappear only after complete conversion of 53 (Scheme 17). 
<smiles>CC(=NCP)C1CCCCC1</smiles>

53<smiles>C#CCNC(C)C1CCCCC1</smiles>

55<smiles>CC(/N=C/c1ccccc1)C1CCCCC1</smiles>

54

Scheme 17

Kinetic studies carried out by our group addressed cyclic imine hydrosilylations on 44 . The results obtained for the hydrosilylation of 2-phenyl-1-pyrroline showed a strong dependence of the yield and ee on the temperature and catalyst concentration [84]. The best results were achieved with $8.5 \mathrm{~mol} \%$ catalyst at $63^{\circ} \mathrm{C}$ with 2.3 mole equivalents of phenylsilane ( $\sim 98 \%$ yield). The phenylsilane concentration had little effect on the reaction rate. The rate expression that was found experimentally was: rate $=\mathrm{k}[\mathrm{Ti}]^{0.5}[\mathrm{C}=\mathrm{N}]^{1.5}$.

\subsection{Catalyst Stability}

Catalyst stability is an important concern, especially in an industrial setting. Catalyst stability is often reported in terms of turnover numbers (TON), i.e., how many cycles a catalyst molecule will complete without deactivation. However, only few TON-data were reported in the literature for chiral titanocenes. Titanocene catalysts are typically highly water sensitive, although traces of water were found to increase the enantioselectivity of some reactions [62]. Most titanocenes in the dichloric, difluoric, or binaphtolate form are air-stable. However, no studies were reported addressing the influence of air moisture on the stability and their air-stability in general. Catalyst stability under reaction conditions was investigated by a few groups.

The chemical transformations of titanocenes in the hydrogenation of alkenes were studied by Brintzinger's group [85], suggesting the following set of reactions:

$$
\begin{aligned}
& {\left[\left(\mathrm{C}_{5} \mathrm{H}_{5}\right)_{2} \mathrm{TiH}\right]_{2}+\mathrm{CH}_{2}=\mathrm{CH}_{2} \rightarrow\left(\mathrm{C}_{5} \mathrm{H}_{5}\right)_{2} \mathrm{TiCH}_{2} \mathrm{CH}_{3}+\left(\mathrm{C}_{5} \mathrm{H}_{5}\right)_{2} \mathrm{TiH}} \\
& \left(\mathrm{C}_{5} \mathrm{H}_{5}\right)_{2} \mathrm{TiCH}_{2} \mathrm{CH}_{3}+\left(\mathrm{C}_{5} \mathrm{H}_{5}\right)_{2} \mathrm{TiH} \rightarrow\left[\left(\mathrm{C}_{5} \mathrm{H}_{5}\right)_{2} \mathrm{Ti}\right]_{2}+\mathrm{CH}_{3} \mathrm{CH}_{3} \\
& {\left[\left(\mathrm{C}_{5} \mathrm{H}_{5}\right)_{2} \mathrm{Ti}\right]_{2}+\mathrm{H}_{2} \rightarrow\left[\left(\mathrm{C}_{5} \mathrm{H}_{5}\right)_{2} \mathrm{TiH}\right]_{2}} \\
& {\left[\left(\mathrm{C}_{5} \mathrm{H}_{5}\right)_{2} \mathrm{Ti}\right]_{2} \rightarrow\left[\left(\mathrm{C}_{5} \mathrm{H}_{5}\right)\left(\mathrm{C}_{5} \mathrm{H}_{4}\right) \mathrm{TiH}\right]_{2} \text { (inactive) }}
\end{aligned}
$$

The titanocene hydride (in dimeric form) reacts with the alkene molecule forming an intermediate complex (1). The interaction of this complex with the titanocene hydride results in elimination of the alkane and re-dimerization of the titanocene (2). This molecule acquires hydrogen to regenerate titanocene hydride (3), or suffers irreversible intramolecular rearrangement due to the fast exchange between hydrogen atoms of cyclopentadiene and titanium hydride (4), leading to deactivation.

Studies on the activity and stability of $\mathrm{Cp}_{2} \mathrm{TiCl}_{2}-\mathrm{n}-\mathrm{BuLi}$ catalysts for alkene hydrogenations showed that high Li-Ti ratios and low titanium concentrations were favorable for high initial activity (the turnover at 1-octene hydrogenation was $7300 \mathrm{~mol}_{\mathrm{H}_{2}} / \mathrm{mol}_{\mathrm{Ti}}$ ), while low Li-Ti ratio and high titanium concentrations resulted in good stability [86, 87]. Different titanocenes were tested for the same reaction in the presence of $\mathrm{NaH}$. The best turnover number $\left(22200 \mathrm{~mol}_{\mathrm{H} 2} / \mathrm{mol}_{\mathrm{Ti}}\right)$ was reached for bis[(1'-ethyl)cyclopentadienyl] $\mathrm{TiCl}_{2} / \mathrm{NaH}$ [88]. In [83] the authors decreased the deactivation rate by 
introduction of bulky substituents into the cyclopentadienyl ring, thus hindering the dimerization. The activity of $\mathrm{di}\left[\left(1\right.\right.$-ethylcyclohexyl)pentadienyl] $\mathrm{TiCl}_{2} / \mathrm{NaH}$ in 1-hexene hydrogenation was even higher, leading to a turnover of $48800 \mathrm{~mol}_{\mathrm{H} 2} / \mathrm{mol}_{\mathrm{Ti}}$. Comparison of the stability of this catalyst with $\mathrm{Cp}_{2} \mathrm{TiCl}_{2} / \mathrm{NaH}$ showed that the substituted titanocene deactivated much slower. The catalytic behavior of both systems (titanocene/n-BuLi or $\mathrm{NaH}$ ) depends on the nature and number of the substituents in the cyclopentadienyl ring, but does not depend significantly on the reducing agent [89].

\section{Heterogenization of Titanocene Catalysts}

Most known titanocene catalysts are homogenous complexes, i.e., they are dissolved in the liquidphase reaction mixture. In contrast to a homogenous reaction system, heterogeneous catalysts offer numerous advantages, such as simple separation and recycling of the expensive catalyst. In the case of pharmaceuticals, leaching of the metal into the active pharmaceutical ingredient (API), which is a significant concern for drug safety, is minimized by using heterogeneous catalysts, which may be removed by filtration. Thus, heterogenization of the catalysts simplifies a process and may reduce the amount of waste [90]. Another potential advantage of the replacement of homogeneous catalysts by immobilized ones is the possibility for bi-functional catalysis, e.g., by creating different types of active sites on the support with improved catalytic performance.

Heterogeneous analogs of most of the commonly used soluble homogeneous catalysts can be prepared by chemical surface modification of a solid support material, followed by grafting of the homogenous complex onto the surface [90]. Among different supports, the most convenient ones are amorphous or mesoporous silicas and silica-rich zeolites. Polymers are another type of potentially useful support materials. Several methodologies exist for attaching organic functional groups onto the surface of a support. They include grafting of functional organosilanes, surface chlorination and subsequent displacement, direct sol-gel preparation of organo-modified silicas and postfunctionalization of existing organic groups on the surface [91]. However, most of the heterogeneous organometallic catalysts were obtained by two principal ways: (i) the sol-gel method and (2) grafting of the surfaces of the inorganic supports [92]. Up to now, no sol-gel methods for titanocene heterogenization were developed.

The first attempt to immobilize titanocenes on solid surfaces was reported thirty years ago [93] with the aim to prevent its dimerization and deactivation. The titanocene was obtained by addition of $\mathrm{CpTiCl}_{3}$ to solid polystyrene, containing cyclopentadienyl groups attached to the surface. The catalytically active species consisted of only monomeric titanocene molecules, and the catalyst activity for alkene hydrogenation was 70 times higher than for the homogeneous titanocene.

Two different ways for the grafting on inorganic surfaces were developed, i.e., (i) via the titanium atom in the complex and (ii) via a tether attached to a ligand (or the bridge) of the complex. Examples for the first method are provided in [94-96], where due to the high reactivity of the titanocenes, they were grafted directly onto a hydroxylated surface of silica. During the impregnation of the silica surface under mild conditions, hydrolysis of the titanium dichloride by the surface silanol groups resulted in the formation of Ti-O-Si bridges on the surface. A number of titanocenes with different ligands were heterogenized on silica and methylaluminoxane-modified silica using this approach [97]. Ansa-bridged titanocene $\left[\mathrm{SiMe}_{2}\left(\eta^{5}-\mathrm{C}_{5} \mathrm{H}_{4}\right)_{2}\right] \mathrm{TiCl}_{2}$ reacted with the hydroxylated surfaces of MCM-41 and MCM-48 at room temperature. If $\mathrm{CH}_{2} \mathrm{Cl}_{2}$ was used as the solvent, the titanocene was anchored to 
the surface without destruction, while it decomposed in THF under formation of the immobilized Ti(IV) species coordinated to THF molecules. Metal loadings of $0.4-0.5 \%$ wt. were achieved. The introduction of bulky substituents into the cyclopentadienyl ring decreased the loading. [98]. In a study by Yun et al. [99] larger titanocene loadings (max. 3\% wt.) were achieved on amorphous silica.

The heterogenized catalysts obtained using this method are not selective for the hydrogenation of double bonds. Thus, another immobilization method is ligand tethering to the surface. For example, a novel ligand on the base of EBTHI, containing functionalized tether was obtained by a multi-step synthesis approach [100]. Several other ligands containing tethers with different functional groups were prepared from 5-bromo-1-[2-(3H-inden-1-yl)ethyl]-3H-indene via Suzuki coupling with substituted phenylboronic acid [101]. Tethering of the titanocene on silica surfaces was reported in [102].

The traditional functional groups on the tether reported in the literature (hydroxyl- carboxyl-, or amino-groups) require surface silanol groups for the immobilization. Because of the high reactivity of titanocene dichloride with silanol groups, formation of the Ti-O-Si bridges cannot be prevented, which may make it difficult to obtain active hydrogenation catalysts. Ofunne et al. [103] anchored catalyst 56 on silica surfaces, which resulted in two types of supported compounds (Scheme 18). In one type (57) of the bound groups, the titanocene was anchored to the surface only with the methoxy groups. In the other type 58, both the $\mathrm{TiCl}_{2}$ group and methoxy group were anchored.

Antberg et al. [104] prepared unbridged and silica-bridged metallocenes of the IV group metals containing two four-carbon tethers with terminal double bond on each cyclopentadienyl by metalation of the corresponding alkenyl-substituted ligands. These metallocenes were successfully heterogenized by reaction with a reduced silica surface in the presence of catalytic amounts of $\mathrm{H}_{2}\left[\mathrm{PtCl}_{6}\right] \cdot 6 \mathrm{H}_{2} \mathrm{O}$ [104].

Attempts to produce tethered di-cyclopentadienyl titanocenes, where only one ligand contains a tether, were mostly unsuccessful [105]. The product, which can be heterogenized onto a surface, was obtained in only $5 \%$ yield. In order to prevent reaction of the titanium dichloride group with the surface hydroxyls, the reaction of $\mathbf{5 6}$ with silica was carried out in toluene at room temperature. After reduction by $\mathrm{BuLi}$, the catalyst displayed a high reactivity for alkene hydrogenations. Surprisingly, the rate of 1-octene hydrogenation (in $\mathrm{cm}_{(\mathrm{H} 2)}^{3} \cdot \mathrm{min}^{-1} \cdot \mathrm{mmol}_{(\mathrm{Ti})}{ }^{-1} \cdot \mathrm{atm}^{-1}$ ) on the catalyst tethered on the silica was 716, while the homogeneous catalyst's rate was only 11.7-30.2. The silica-supported catalyst appeared not only more active, but also more selective for 1-alkenes. Its stability was also higher: the rate of 1-octene hydrogenation decreased by a factor of 2 after 32 minutes, but still showed high activity after 2 days, while the homogeneous catalyst, which is much less active, almost completely lost its activity after $12 \mathrm{~min}$. This stabilizing effect can be explained by the inhibition of the transformation of the titanocene into a catalytically inactive dimeric complex. 


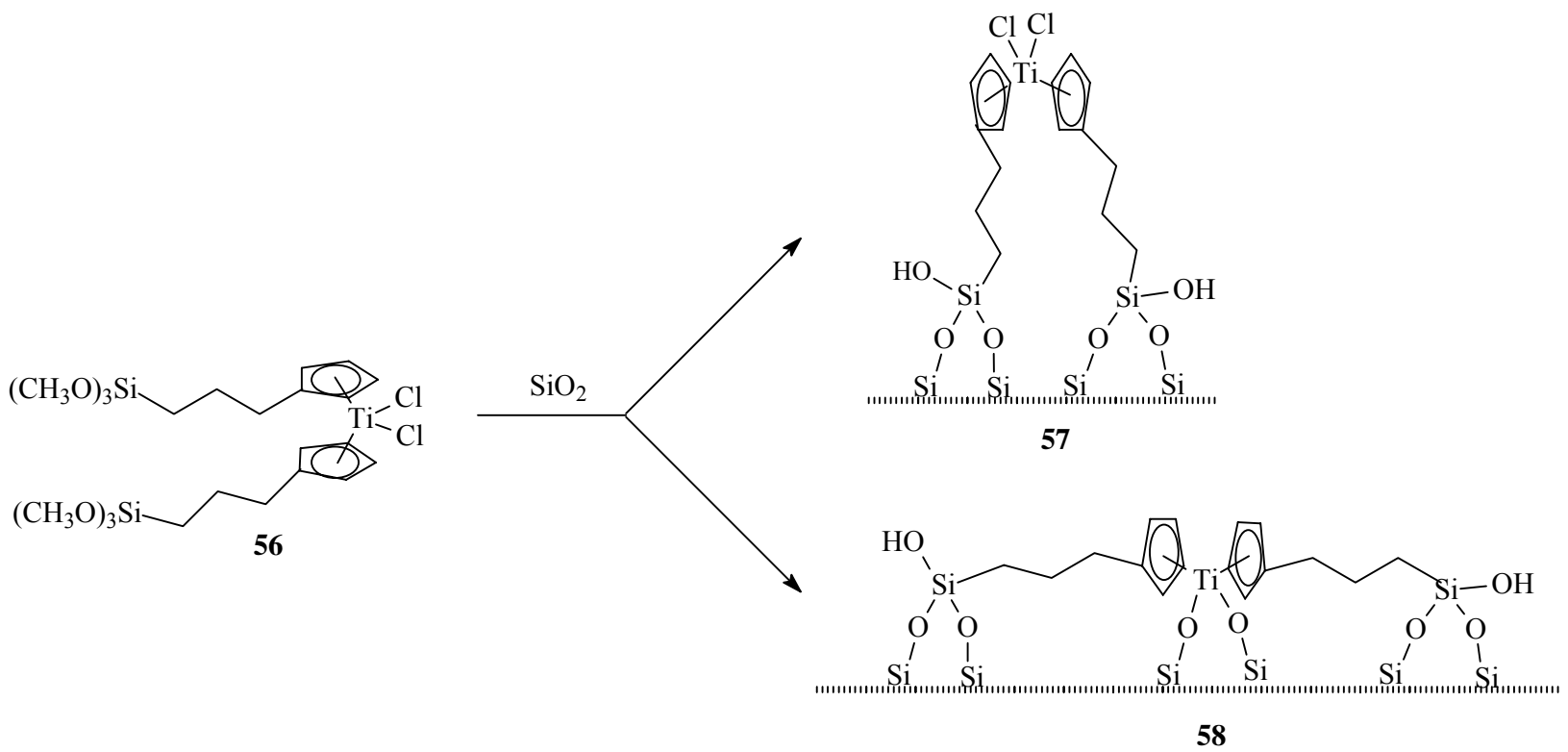

Scheme 18

A promising strategy for the immobilization of titanocenes by tether only, without the risk of titanium dichloride destruction, is to use a tether with terminal double bonds. This functional group can react with silica hydride groups on the reduced silica surface, while the destructive silanol groups can be neutralized by treatment with trimethylchlorosilane. For this reason, a new ligand with tethers containing double bond was synthesized via Suzuki coupling [101,106]. The ligand was later successfully metalated with titanium (complex 59) and immobilized on a dehydroxylated silica hydride surface, yielding the heterogenized titanocene 60 (Scheme 19). No further studies exist on the heterogenization of titanocenes.
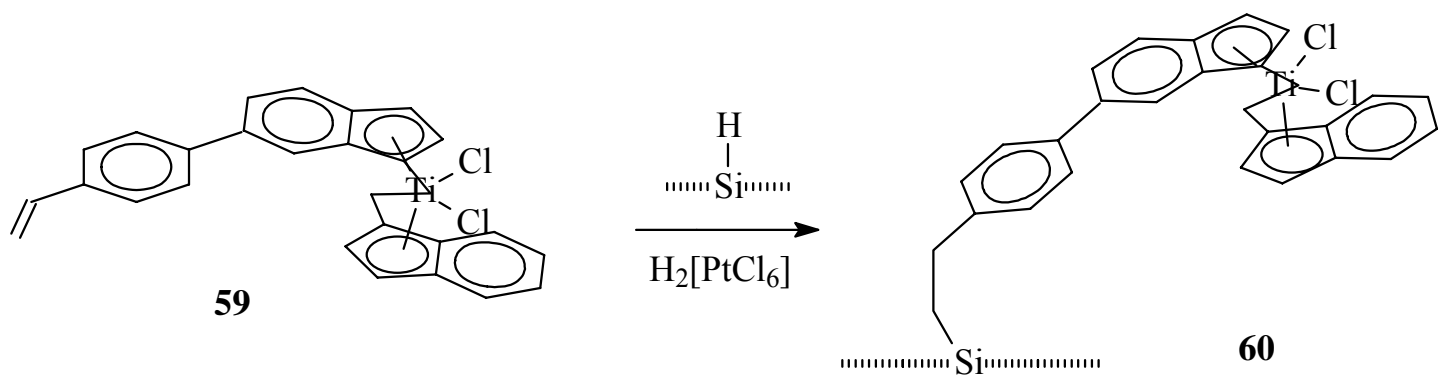

\section{Scheme 19}

\section{Summary and Outlook}

Homogeneous chiral titanocenes are active and selective catalysts for the hydrogenation of a number of compounds containing double bonds. One of the advantages of titanocenes over many other catalysts (such as the catalytically active complexes of group VIII metals $[107,108]$ ) is that no coordinating groups are needed to achieve a high degree of enantioselectivity of the hydrogenation. Titanocene catalysts discriminate isomers based on the shape of the substrate only. In addition, the tailoring of the ligands allows precise stereocontrol for a wide variety of reactions and substrates. 
However, a review of the scientific and patent literature reveals that no processes with chiral titanocenes for stereoselective hydrogenations have been commercialized to date - for various reasons. First, the development of new ligands has been tightly controlled by a few companies via stringent patent rights, and the main emphasis of these companies has not been in the area of stereoselective hydrogenations. Second, there are no studies in the open literature that address the optimization of an actual reaction system. Although the TOFs of certain complexes (for example, EBTHI-TiF 2 ) are close to what is needed for industrial applications, no systematic studies on the reaction kinetics (TOF, TON, stability, solvent and co-solvent effects, temperature and pressure dependence, additives, etc.) have been performed. Third, the cost of product purification and the expensive catalyst recovery are major drawbacks. In order to overcome these problems, we propose the following:

- Increased academic research in close collaboration with industry should lead to a wider variety of ligands, complexes and reaction systems.

- Detailed and precise kinetic studies and the optimization of actual reaction systems need to be performed in order to fully exploit the potential of titanocenes in stereoselective hydrogenations. Furthermore, reactor and process design have to be integrated in the development of an actual catalytic reaction system [109]. Here, chemical engineers and chemists should interact closely.

- Computational chemistry should become a design tool for new catalysts. Computational chemistry has reached a level, where it is possible to make predictions to help guide experimental directions, resulting in more efficient use of experimental resources. Experiments will provide testing and calibration of the computational models, which in turn increases their value as experimental tools.

- Heterogenization of catalysts and the development of new and more effective heterogenization methods may further increase the applicability and value of these systems.

In summary, chiral titanocenes are important catalysts in the toolbox of the industrial chemist. However, further optimization is needed to fully exploit their potential.

\section{References}

1. Cole-Hamilton, D. Why asymmetric catalysis won the 2001 Nobel prize. IAS News 2002, 9, 4-5.

2. Stinson, S. C. Chiral chemistry. Chem. Eng. News 2001, 79, 45-57.

3. Reetz, M. T. Strategies for the development of enantioselective catalysts. Pure Appl. Chem. 1999, 71, 1503-1509.

4. James, B. R.; Synthesis of chiral amines catalyzed homogeneously by metal complexes. Catal Today 1997, 37, 209-221.

5. Blaser, H. U.; Malan, C.; Pugin, B.; Spindler, F.; Steiner, H.; Studer, M. Selective hydrogenation for fine chemicals: recent trends and new developments. Adv. Synth. Catal. 2003, 345, 103-151.

6. Blaser, H. U.; Spindler, F.; Studer, M. Enantioselective catalysis in fine chemicals production. Appl. Catal. A: (General) 2001, 221, 119-143.

7. Cuenca, T.; Flores, J. C.; Royo, P. Dicyclopentadienyltitanium and -zirconium complexes as catalysts for hydrogenation of olefins. J. Organomet. Chem. 1993, 462, 191-201.

8. Halterman, R. L.; Togni A. (eds.). Metallocenes; Wiley: New York, 1998.

9. Halterman, R. L. Synthesis and applications of chiral cyclopentadienylmetal complexes. Chem. Rev. 1992, 92, 965-94. 
10. Besancon, J.; Tirouflet, J.; Top, S.; Ea, B. H. Titanocene derivatives having two pentahapto ligands with planar chirality. Separation and identification of different stereochemical forms. $J$. Organomet. Chem. 1977, 133, 37-51.

11. Cesarotti, E.; Kagan, H. B.; Goddard, R.; Kruger, C. Synthesis of new ligands for transition metal complexes: menthyl- and neomenthylcyclopentadienes. J. Organomet. Chem. 1978, 162, $297-$ 309.

12. Paquette, L. A.; Sivik, M. R.; Bzowej, E. I.; Stanton, K. J. Catalytic enantioselective hydrogenation of 1,1-disubstituted olefins with optically active titanocene and zirconocene complexes containing either identical or different ligands. Organometallics 1995, 14, 4865-4878.

13. Halterman, R. L.; Vollhardt, K. P. C.; Welker, M. E.; Blaser, D.; Boese, R. A designed, enantiomerically pure, fused cyclopentadienyl ligand with $\mathrm{C}_{2}$ symmetry. Synthesis and use in enantioselective titanocene-catalyzed hydrogenations of alkenes. J. Am. Chem. Soc. 1987, 109, 8105-8107.

14. Chen, Z.; Eriks, K.; Halterman, R. L. Asymmetric synthesis and metalation of $\mathrm{C}_{2}$-symmetric annulated bicyclooctylcyclopentadienes. Organometallics 1991, 10, 3449-3458.

15. Paquette, L. A.; Moriarty, K. J.; Menunier, P.; Gautheron, B.; Crocq, V. Isodicyclopentadienes and related molecules. Part 40. Stereocontrolled bifacial complexation of the isodicyclopentadienyl ligand to cyclopentadienyltitanium dichloride fragments. Organometallics 1988, 7, 18731875 .

16. Halterman, R. L.; Tretyakov, A. Synthesis of camphor-derived chiral cyclopentadienes via the Nazarov cyclization: preparation of chiral cis(cyclopentadienyl)zirconium and -titanium dichlorides. Tetrahedron 1995, 51, 4371-4382.

17. Yang, Q.; Jensen, M. D. Novel and efficient syntheses of bis $\left(\eta^{5}\right.$-tetrahydroindenyl) dichlorides of titanium, zirconium and hafnium. Synlett 1996, 6, 563-564.

18. Bajgur, C. S.; Tikkanen, W. R.; Petersen, J. L. Synthesis, structural characterization, and electrochemistry of [1]metallocenophane complexes, [Si(alkyl $\left.)_{2}\left(\mathrm{C}_{5} \mathrm{H}_{4}\right)_{2}\right] \mathrm{MCl}_{2}, \mathrm{M}=\mathrm{Ti}$, Zr. Inorg. Chem. 1985, 24, 2539-2546.

19. Smith, J. A.; Brintzinger, H. H. Ansa-metallocene derivatives. III. Influence of an interannular ethylene bridge on the reactivity of titanocene derivatives. J. Organomet. Chem. 1981, 218, 15967.

20. Collins, S.; Kuntz, B. A.; Taylor, N. J.; Ward, D. G. X-ray structures of ethylenebis(tetrahydroindenyl)titanium and -zirconium dichlorides: a revision. J. Organomet. Chem. 1988, 342, 21-9.

21. Huttenloch, M. E.; Dorer, B.; Rief, U.; Prosenc, M.-H.; Schmidt, K.; Brintzinger, H. H.. ansaMetallocene derivatives. XXXIX. Biphenyl-bridged metallocene complexes of titanium, zirconium, and vanadium: syntheses, crystal structures and enantioseparation. J. Organomet. Chem. 1997, 541, 219-232.

22. Shapiro, P. J. The evolution of the ansa-bridge and its effect on the scope of metallocene chemistry. Coord. Chem. Rev. 2002, 231, 67-81.

23. Schnutenhaus, H.; Britzinger H.H. ansa-Metallocenes. 2. 1,1'-Trimethylene-bis( $\eta 5-3-t e r t-$ butylcyclopentadienyl)titanium(IV) dichloride, a chiral ansa-titanocene derivative. Angew. Chem. 1979, 91, 837-838. 
24. Wild, F. R. W. P.; Zsolnai, L.; Huttner, G.; Brintzinger, H. H. ansa-Metallocene derivatives. IV. Synthesis and molecular structures of chiral ansa-titanocene derivatives with bridged tetrahydroindenyl ligands. J. Organomet. Chem. 1982, 232, 233-47.

25. Nantz, M. H.; Hitchcock, S. R.; Sutton, S. C.; Smith, M. D. A disulfone-based approach to ansatitanocenes: synthesis of ethylene bis(2-indenyl)titanium dichloride. Organometallics 1993, 12, 5012-5015.

26. Hitchcock, S. R.; Situ, J. J.; Covel, J. A.; Olmstead, M. M.; Nantz, M. H. Synthesis of ansatitanocenes from 1,2-bis(2-indenyl)ethane and structural comparisons in the catalytic epoxidation of unfunctionalized alkenes. Organometallics 1995, 14, 3732-3740.

27. Kelly, P. A.; Berger, G. O.; Wyatt, J. K.; Nantz, M. H. Synthesis of [ethylene-1-( $\eta^{5}-4,5,6,7-$ tetrahydro-1-indenyl)-2-( $\eta^{5}-4^{\prime}, 5^{\prime}, 6^{\prime}, 7^{\prime}$-tetrahydro-2'-indenyl)]titanium dichloride, the elusive isomer of the Brintzinger-type ansa-titanocenes. J. Org. Chem. 2003, 68, 8447-8452.

28. Palandoken, H.; Wyatt, J. K.; Hitchcock, S. R.; Olmstead, M. M.; Nantz, M. H. Reductive dehydroxy coupling of 2-(hydroxymethyl)indenes to prepare ethano-bridged bis(2-indenyl) ansatitanocenes. J. Organomet. Chem. 1999, 579, 338-347.

29. Halterman, R. L.; Ramsey, T. M.; Pailes, N. A.; Khan, M. A. Application of the double PausonKhand cyclization to the synthesis of bis(cyclopentadienes): preparation of phenyl-bridged bis(tetrahydroindenyl)titanium and zirconium dichlorides. J. Organomet. Chem. 1995, 497, 43-53.

30. Huttenloch, M. E.; Diebold, J.; Rief, U.; Brintzinger, H. H.; Gilbert, A. M.; Katz, T. J. ansaMetallocene derivatives. 26. Biphenyl-bridged metallocenes that are chiral, configurationally stable, and free of diastereomers. Organometallics 1992, 11, 3600-3607.

31. Halterman, R. L.; Ramsey, T. M. Asymmetric synthesis of a sterically rigid binaphthyl-bridged chiral metallocene: asymmetric catalytic epoxidation of unfunctionalized alkenes. Organometallics 1993, 12, 2879-80.

32. Burk, M. J.; Colletti, S. L.; Halterman, R. L. C 2 -symmetric 2,2'-dimethyl-1,1'-binaphthyl-bridged ansa-bis(1-indenyl)metal complexes. Organometallics 1991, 10, 2998-3000.

33. Halterman, R. L.; Zhu, C.; Chen, Z.; Dunlap, M. S.; Khan, M. A.; Nicholas, Kenneth M. Preparation of [2,5-diisopropylcyclohexane-1,4-bis(indenyl)]titanium dichloride and [2,5diisopropylcyclohexane-1,4-bis(tetrahydroindenyl)]- titanium dichloride and their comparison as catalysts for the enantioselective pinacol coupling of benzaldehyde. Organometallics 2000, 19, 3824-3829.

34. Halterman, R. L.; Combs, D.; Kihega, J.; Khan, M. A. Synthesis of ansa-2,2'-bis[(4,7dimethylinden-1-yl)methyl]-1,1'-binaphthyl and ansa-2,2'-bis[(4,5,6,7-tetrahydroinden-1yl)methyl]-1,1'-binaphthyltitanium and -zirconium dichlorides. J. Organomet. Chem. 1996, 520, 163-170.

35. Halterman, R. L.; Schumann, H.; Dubner, F. Synthesis and structure of ansa-metallocene complexes $\left(\mathrm{M}=\mathrm{ZrCl}_{2}, \mathrm{TiCl}_{2}, \mathrm{YCl}\right.$, and $\left.\mathrm{LuCl}\right)$ containing the bis(2-methyl-4,5,6,7tetrahydroindenyl)dimethylsilane ligand. J. Organomet. Chem. 2000, 604, 12-19.

36. Chen, Z.; Halterman, R. L. Enantioselective catalytic isomerization of an unfunctionalized achiral alkene. J. Amer. Chem. Soc. 1992, 114, 2276-2277.

37. Chen, Z.; Halterman, R. L. Chiral cyclopentane-1,3-diyl-bridged ansa-titanocene dichlorides. Organometallics 1994, 13, 3932-3942. 
38. Roell, W.; Zsolnai, L.; Huttner, G.; Brintzinger, H. H. ansa-Metallocene derivatives. XI. Synthesis and crystal structure of a chiral ansa-titanocene derivative with trimethylene bridged tetrahydroindenyl ligands. J. Organomet. Chem. 1987, 322, 65-70.

39. Horacek, M.; Stepnicka, P.; Gyepes, R.; Cisarova, I.; Tislerova, I.; Zemanek, J.; Kubista, J.; Mach, K. Reduction of bis $\left[\eta^{5}-(\omega\right.$-alkenyl)tetramethylcyclopentadienyl]titanium dichlorides: an efficient synthesis of long-chain ansa-bridged titanocene dichlorides by acidolysis of cyclopentadienylring-tethered titanacyclopentanes. Chem. A Eur. J. 2000, 6, 2397-2408.

40. Gibis, K.-L.; Helmchen, G; Huttner, G.; Zsolnai, L. Enantiomerically pure $\mathrm{C}_{2}$-symmetric bridged ferrocene and titanocene derivatives. J. Organomet. Chem. 1993, 445, 181-186.

41. Halterman, R. L.; Chen, Z.; Khan, M. A. Synthesis, structure determination, and reactivity of $\mathrm{C}_{2^{-}}$ symmetrical ethylene-bridged ansa-Bis(DiMeBCOCp)titanium dichlorides. Organometallics 1996, 15, 3957-3967.

42. Willoughby, C. A.; Davis, W. M.; Buchwald, S. L. Preparation and X-ray structure of a novel chiral methylene bridged titanocene complex. J. Organomet. Chem. 1995, 497, 11-15.

43. Wiesenfeldt, H.; Reinmuth, A.; Barsties, E.; Evertz, K.; Brintzinger, H. H. ansa-Metallocene derivatives. XVII. Racemic and meso diastereomers of Group IV metallocene derivatives with symmetrically substituted, dimethylsilanediyl-bridged ligand frameworks. Crystal structure of R,S-Me ${ }_{2} \mathrm{Si}\left(3-\text { tert-Bu-5- } \mathrm{MeC}_{5} \mathrm{H}_{2}\right)_{2} \mathrm{ZrCl}_{2}$. J. Organomet. Chem. 1989, 369, 359-370.

44. Mise, T.; Miya, S.; Yamazaki, H. Excellent stereoregular isotactic polymerizations of propylene with $\mathrm{C}_{2}$-symmetric silylene-bridged metallocene catalysts. Chem. Lett. 1989, 10, 1853-1856.

45. Lee, M. H.; Han, Y.; Kim, D.; Hwang, J.-W.; Do, Y. Isospecific propylene polymerization by $\mathrm{C}_{1^{-}}$ symmetric $\mathrm{Me}_{2} \mathrm{Si}_{(}\left(\mathrm{C}_{5} \mathrm{Me}_{4}\right)\left(2-R\right.$-Ind) $\mathrm{MCl}_{2}(\mathrm{M}=\mathrm{Ti}, \mathrm{Zr})$ complexes. Organometallics 2003, 22, 2790-2796.

46. Antinolo, A.; Fajardo, M.; Gomez-Ruiz, S.; Lopez-Solera, I.; Otero, A.; Prashar, S.; Rodriguez, A. M. Group 4 metallocene complexes incorporating vinyl or allyl substituted ansa ligands. X-Ray crystal structures of $\left[\mathrm{Zr}\left\{\mathrm{Me}\left(\mathrm{CH}_{2}: \mathrm{CH}\right) \mathrm{Si}\left(\eta^{5}-\mathrm{C}_{5} \mathrm{Me}_{4}\right)_{2}\right\} \mathrm{Cl}_{2}\right]$, $\left[\mathrm{Zr}\left\{\mathrm{Me}\left(\mathrm{CH}_{2}: \mathrm{CHCH}_{2}\right) \mathrm{Si}\left(\eta^{5}-\mathrm{C}_{5} \mathrm{H}_{4}\right)_{2}\right\} \mathrm{Cl}_{2}\right]$ and $\left[\mathrm{Zr}\left\{\mathrm{Me}\left(\mathrm{CH}_{2}: \mathrm{CHCH}_{2}\right) \mathrm{Si}\left(\eta^{5}-\mathrm{C}_{5} \mathrm{Me}_{4}\right)\left(\eta^{5}-\mathrm{C}_{5} \mathrm{H}_{4}\right)\right\} \mathrm{Cl}_{2}\right]$. J. Organomet. Chem. 2003, 683, 11-22.

47. Grossman, R. B.; Tsai, J.-C.; Davis, W. M.; Gutierrez, A.; Buchwald, S. L. Synthesis and structure of a $\mathrm{C}_{2}$-symmetric, doubly bridged ansa-titanocene complex. Organometallics 1994, 13, 3892-3896.

48. Halterman, R. L.; Tretyakov, A.; Combs, D.; Chang, J.; Khan, M. A. Synthesis and structure of $\mathrm{C}_{2}$-symmetric, doubly bridged bis(indenyl)titanium and -zirconium dichlorides. Organometallics 1997, 16, 3333-3339.

49. Dorer, B.; Prosenc, M.-H.; Rief, U.; Brintzinger, H. H. ansa-Metallocene derivatives. 30. syntheses and structures of titanocene, zirconocene, and vanadocene dichloride complexes with two ethanediyl bridges. Organometallics 1994, 13, 3868-3872.

50. Cano, A.; Cuenca, T.; Gomez-Sal, P.; Royo, B.; Royo, P. Double-dimethylsilyl-bridged dicyclopentadienyl group 4 metal complexes. X-ray molecular structures of $\mathrm{M}\left[\left(\mathrm{Me}_{2} \mathrm{Si}\right)_{2}\left(\eta^{5}-\right.\right.$ $\left.\left.\mathrm{C}_{5} \mathrm{H}_{3}\right)_{2}\right] \mathrm{Cl}_{2}(\mathrm{M}=\mathrm{Ti}, \mathrm{Zr})$ and $\left(\mathrm{TiCl}_{3}\right)_{2}\left\{\mu-\left[\left(\mathrm{Me}_{2} \mathrm{Si}\right)_{2}\left(\eta^{5}-\mathrm{C}_{5} \mathrm{H}_{3}\right)_{2}\right]\right\}$. Organometallics 1994, 13, $1688-$ 1694.

51. Cano, A.; Cuenca, T.; Gomez-Sai, P.; Manzanero, A; Royo P. Dicyclopentadienyl titanium and zirconium complexes with the double bridged bis(dimethylsilanodiyl) dicyclopentadienyl 
$\left[\left(\mathrm{Me}_{2} \mathrm{Si}\right)_{2}\left(\eta^{5}-\mathrm{C}_{5} \mathrm{H}_{3}\right)_{2}\right]_{2}$-ligand: X-ray molecular structure of $\left[\mathrm{Ti}\left\{\left(\mathrm{SiMe}_{2}\right)_{2}\left(\eta^{5}-\mathrm{C}_{5} \mathrm{H}_{3}\right)_{2}\right\} \mathrm{Me}_{2}\right] . \quad J$. Organomet. Chem. 1996, 526, 227-235.

52. Bercaw J. E.; Brintzinger, H. H. A metastable form of titanocene. Formation from a hydride complex and reactions with hydrogen, nitrogen, and carbon monoxide. J. Am. Chem. Soc. 1971, 93, 2046-2048.

53. Chin, B.; Buchwald, S. L. An Improved procedure for the resolution of (rac)ethylenebis(tetrahydroindenyl)titanium derivatives J. Org. Chem. 1996, 61, 5650-5651.

54. Verdaguer, X.; Lange, U. E. W.; Reding, M. T.; Buchwald, S. L. Highly enantioselective imine hydrosilylation using (S,S)-ethylenebis(-tetrahydroindenyl)titanium difluoride. J. Am. Chem. Soc. 1996, 118, 6784-6785.

55. Buchwald, S. L.; Broene, R. D. Catalytic asymmetric reduction of trisubstituted olefins. US Pat. 5442119, 1995.

56. Buchwald, S. L.; Lee, N. E. Catalytic asymmetric reduction of enamines. US Pat. 5489682, 1996.

57. Buchwald, S. L.; Broene, R. D.; Lee, N. E. Catalytic asymmetric reduction of trisubstituted olefins. US Pat. 5491233, 1996.

58. Buchwald S. L.; Lee, N. E.; Broene, R. D. Catalytic asymmetric reduction of trisubstituted olefins and enamines. WO Pat. 9502567 A1, 1995.

59. Sloan, M. F.; Matlack, A. S.; Breslow, D. S. Soluble catalysts for the hydrogenation of olefins. J. Am. Chem. Soc. 1963, 85, 4014-4018.

60. Cesarotti, E.; Ugo, R.; Vitiello, R. Chiral cyclopentadienyl[s] as ligands in homogeneous asymmetric catalysis. Part 1. Asymmetric hydrogenation of simple olefins by titanium(IV) complexes. J. Mol. Catal. 1981, 12, 63-9.

61. Halterman, R. L.; Vollhardt, K. P. C. Synthesis and asymmetric reactivity of enantiomerically pure cyclopentadienylmetal complexes derived from the chiral pool. Organometallics 1988, 7 , 883-892.

62. Beagley, P.; Davies, P. J.; Blacker, A. J.; White, C. Chiral metallocenes. 3. The enantioselective reduction of $\mathrm{C}=\mathrm{X}$ bonds $\left(\mathrm{X}=\mathrm{O}\right.$ or $\left.\mathrm{CH}_{2}\right)$ by the chiral ansa-metallocenes $(R)$ - or $(S)-\left[\mathrm{TiCl}_{2}\left(\eta^{5}: \eta^{5}\right.\right.$ $\left.\left.\mathrm{C}_{5} \mathrm{Me}_{4} \mathrm{SiMe}_{2} \mathrm{C}_{5} \mathrm{H}_{3} \mathrm{R}^{*}\right)\right]$ ( $\mathrm{R}^{*}=$ menthyl or neomenthyl). Organometallics 2002, 21, 5852-5858.

63. Willoughby, C. A.; Buchwald, S. L. Asymmetric titanocene-catalyzed hydrogenation of imines. J. Am. Chem. Soc. 1992, 114, 7562-7564.

64. Willoughby, C. A.; Buchwald, S. L. Catalytic asymmetric hydrogenation of imines with a chiral titanocene catalyst: scope and limitations. J. Am. Chem. Soc. 1994, 116, 8952-8965.

65. Willoughby, C. A.; Buchwald, S. L. Synthesis of highly enantiomerically enriched cyclic amines by the catalytic asymmetric hydrogenation of cyclic imines. J. Org. Chem. 1993, 58, 7627-7629.

66. Lee, N. E.; Buchwald, S. L. Asymmetric Hydrogenation of enamines with a chiral titanocene catalyst. J. Am. Chem. Soc. 1994, 116, 5985-5986.

67. Verdaguer, X.; Lange, U. E. W.; Buchwald, S. L. Imine hydrosilylation, uses and reagents related thereto. US Pat. 6072085, 2000.

68. Tillack, A.; Lefeber, C.; Peulecke, N.; Thomas, D.; Rosenthal, U. The hydrosilylation of ald- and ketimines catalyzed by titanocene complexes. Tetrahedron Lett. 1997, 38, 1533-1534.

69. Viso, A.; Lee, N. E.; Buchwald S. L. Kinetic resolution of racemic disubstituted 1-pyrrolines via asymmetric reduction with a chiral titanocene catalyst. J. Am. Chem. Soc. 1994, 116, 9373-9374. 
70. Yun, J.; Buchwald, S. L. Efficient kinetic resolution in the asymmetric hydrosilylation of imines of 3-substituted indanones and 4-substituted tetralones. J. Org. Chem. 2000, 65, 767-774.

71. Yamamoto, K.; Uramoto, Y.; Kumada, M. Asymmetric hydrosilylation with a chiral phosphinenickel(II) complex. J. Organom. Chem., 1971, 31, C9-C10.

72. Halterman, R. L.; Ramsey, T. M.; Chen, Z. Catalytic asymmetric hydrosilation of aryl alkyl ketones with $\mathrm{C}_{2}$-symmetric chiral metallocene complexes. J. Org. Chem. 1994, 59, 2642-2644.

73. Carter, M. B.; Schiott, B.; Gutierrez, A.; Buchwald, S. L. Enantioselective hydrosilylation of ketones with a chiral titanocene catalyst. J. Am. Chem. Soc. 1994, 116, 11667-11670.

74. Rahimian, K.; Harrod, J. F. The Influence of the catalyst preparation protocol and silane structure on the rate and enantioselectivity of ansa-titanocene catalysed hydrosilylation of prochiral ketones. Inorg. Chim. Acta 1998, 270, 330-336

75. Hironori, I.; Mori, M.; Nakai, T. Asymmetric catalytic hydrosilylation of ketones with triethoxysilane using a chiral binaphtol-titanium complex. Synlett 1996, 12, 1229-1230.

76. Beagley, P.; Davies, P.; Adams, H.; White, C. Chiral metallocenes: the synthesis and X-ray crystal structures of $\mathrm{TiCl}_{2}\left(\eta^{5}: \eta^{5}-\mathrm{C}_{5} \mathrm{Me}_{4} \mathrm{SiMe}_{2} \mathrm{C}_{5} \mathrm{H}_{3} \mathrm{R}^{*}\right)\left(\mathrm{R}^{*}=\right.$ menthyl or neomenthyl $)$ and related compounds. Can. J. Chem., 2001, 79, 731-741.

77. Broene, R. D.; Buchwald, S. L. Asymmetric hydrogenation of unfunctionalized trisubstituted olefins with a chiral titanocene catalyst. J. Am. Chem. Soc. 1993, 115, 12569-12570.

78. Willoughby, C. A.; Buchwald, S. L. Catalytic asymmetric hydrogenation of imines with a chiral titanocene catalyst: kinetic and mechanistic investigations. J. Am. Chem. Soc. 1994, 116, $11703-$ 11714.

79. Lee, S. J.; Han, B. H. Hydrosilylation of olefins catalyzed by activated titanocene prepared from the reduction of titanocene dichloride with excess lithium. Main Group Metal Chem. 1998, 21, 315-318.

80. Takahashi, T.; Bao, F.; Gao, G.; Ogasawara, M. Titanocene-catalyzed regioselective synhydrosilylation of alkynes. Org. Lett. 2003, 5, 3479-3481.

81. Verdaguer, X.; Lange, U. E. W.; Buchwald, S. L. Amine additives greatly expand the scope of asymmetric hydrosilylation of imines. Angew. Chem. Int. Ed. 1998, 37, 1103-1107.

82. Yun, J.; Buchwald, S. L. Titanocene-catalyzed asymmetric ketone hydrosilylation: the effect of catalyst activation protocol and additives on the reaction rate and enantioselectivity. J. Am. Chem. Soc. 1999, 121, 5640-5644.

83. Fan, Y.-H.; Liao, S.-J.; Xu, J.; Wang, F.-D.; Qian, Y.-L.; Huang, J.-L. Extremely active catalysts for the hydrogenation of terminal alkenes. J. Catal. 2002, 205, 294-298.

84. Woelfler, H.; Panarello, A.; Zaborenko, N.; Raupenstrauch H.; Khinast, J. G. Homogeneous titanocene catalysts for stereoselective reductions: kinetic investigations and mechanistic studies. Abstr. 14 Int. Symp. On Homogeneous Catalysis; Munich, Germany, 2004.

85. Bercaw, J. E.; Marvich, R. H.; Bell, L. G.; Brintzinger, H. H. Titanocene as an intermediate in reactions involving molecular hydrogen and nitrogen. J. Am. Chem. Soc. 1972, 94, 1219-1232.

86. Sun, Q.; Liao, S.; Xu, Y.; Zhang, Y.; Yang, R.; Sun, R. Activity and stability of $\mathrm{Cp}_{2} \mathrm{TiCl}_{2} / n-\mathrm{BuLi}$ catalyst system for the hydrogenation of olefins. Cuihua Xuebao 1997, 18, 147-151; [Chem. Abstr. 126:239863]. 
87. Liao, S. J.; Xu, Y.; Zhang, Y. P.; Sun, Q.; Sun, R. A.; Yang, R. W. Factors affecting the catalytic activities of the $\mathrm{Cp}_{2} \mathrm{TiCl}_{2} / \mathrm{n}$-BuLi system for the olefin hydrogenation. Chin. Chem. Lett. 1994, 5, 689-692.

88. Fan, Y.-H.; Liao, S.-J.; Xu, J.; Qian, Y.-L.; Huang, J.-L. Highly active hydrogenation catalysts from titanocenes and sodium hydride of nanometric size. Gaodeng Xuexiao Huaxue Xuebao 1997, 18, 1683-1687; [Chem. Abstr. 127:307091].

89. Sun, Q.; Sun, R. Hydrogenation of olefins catalyzed by highly active titanocene/NaH or $n$-BuLi catalyst systems. Chem. Res. Chin. Univ. 2002, 18, 307-310; [Chem. Abstr. 138:122308].

90. De Vos, D. E.; Vankelecom, I. F. J.; Jacobs, P. A., Eds. Chiral catalyst immobilization and recycling; Wiley-VCH: Weinheim (Germany), 2000.

91. Clark, J. H.; Macquarrie, D. J. Catalysis of liquid phase organic reactions using chemically modified mesoporous inorganic solids. Chem. Commun. 1998, 8, 853-860.

92. Clark, J. H. Catalysis for green chemistry. Pure Appl. Chem. 2001, 73, 103-111.

93. Bonds, W. D., Jr.; Brubaker, C. H., Jr.; Chandrasekaran, E. S.; Gibbons, C.; Grubbs, R. H.; Kroll, L. C. Polystyrene attached titanocene species. Preparation and reactions. J. Amer. Chem. Soc. 1975, 97, 2128-2132.

94. Corma, A.; Diaz, U.; Fornes, V.; Jorda, M. D.; Rey, F. Ti/ITQ-2, a new material highly active and selective for the epoxidation of olefins with organic hydroperoxides. Chem. Commun. 1999, 9, 779-780.

95. Maschmeyer, T.; Rey, F.; Sankar, G.; Thomas, J. M. Heterogeneous catalysts obtained by grafting metallocene complexes onto mesoporous silica. Nature (London) 1995, 378, 159-62.

96. Capka, M.; Reissova, A. Hydrogenation activity of homogeneous and heterogenized cyclopentadienyl titanium complexes. Coll. Czech. Chem. Comm. 1989, 54, 1760-1769.

97. Ferreira, P.; Goncalves, I. S.; Kuhn, F. E.; Pillinger, M.; Rocha, J.; Santos, A. M.; Thursfield, A. Structural studies and catalytic activity of MCM-41 and MCM-48 modified with the titanocenophane $\left[\mathrm{SiMe}_{2}\left(\eta^{5}-\mathrm{C}_{5} \mathrm{H}_{4}\right)_{2}\right] \mathrm{TiCl}_{2}$. Eur. J. Inorg. Chem. 2000, 3, 551-557.

98. Guimaraes, R.; Stedile, F. C.; dos Santos, J. H. Z. Ethylene polymerization with catalyst systems based on supported metallocenes with varying steric hindrance. J. Mol. Catal. A: Chem. 2003, 206, 353-362.

99. Yun, S.-H.; Bu, J.; Rhee, H.-K. Grafting titanocene on hydrophilic amorphous silica: synthesis of an effective catalyst for olefin epoxidation. React. Kinet. Catal. Lett. 2001, 72, 343-353.

100. Panarello, A. P.; Khinast, J. G. Synthesis of a novel ethylene-bis(tetrahydroindenyl) ligand containing a functionalized four-carbon tether. Tetr. Lett. 2003, 44, 4095-4098.

101. Panarello, A.; Vassylyev, O.; Khinast, J. G. Selective alkylation and Suzuki Coupling as a strategy for introducing functional anchors to the ethylene-bis(indenyl) ligand. Tetrahedron Lett. 2005, 46, 1353-1356

102. Panarello, A.; Woelfler, H., Vassylyev, O.; Raupenstrauch H. and Khinast, J. G. Synthesis and kinetic investigation of a novel chiral heterogeneous titanocene catalyst. Abstr. 2003 AIChE Ann. Meet., San Francisco, CA, 2003, abstr. 511e.

103. Ofunne, G. C.; Booth, B. L.; Tait, P. J. T. Characterization and polymerization studies on silicasupported titanium (IV) complexes. Ind. J. Chem. 1988, 27A, 1040-1046. 
104. Antberg, M.; Boehm, L.; Rohrmann, J. Process for the preparation of a heterogeneous metallocene catalyst component. US Pat. 5071808, 1991.

105. Booth, B. L.; Ofunne, G. C.; Stasey, C. and Tait, P. J. T. Silica-supported cyclopentadienylrhodium(I), -cobalt(I), and -titanium(IV) complexes. J. Organomet. Chem. 1986, 315, 143-156.

106. Panarello, A.; Vassylyev, O.; Khinast, J. G. Preparation of a novel heterogeneous titanocene catalyst for chiral reduction and asymmetric polymerization. Abstr. $228^{\text {th }}$ ACS Nat. Meet., Philadelphia, PA, 2004.

107. Wiles, J. A.; Bergens, S. H. Mechanistic investigations of an enantioselective hydrogenation catalyzed by a ruthenium-BINAP complex. 1. Stoichiometric and catalytic labelling studies. Organometallics 1998, 17, 2228-2240.

108. Surpateanu, G.; Agbossou, F.; Carpentier, J.-F.; Mortreux, A. Rhodium dihydride complexes as models for the theoretical analysis of enantioselective hydrogenation reactions. Tetr. Asymmetr. 1998, 9, 2259-2270.

109. Chaudhari, R. V. Kinetics of catalytic reactions. In "Catalysis: Principles and Applications"; Viswanathan, B.; Sivasanker, S.; Ramaswamy, A. V., Eds.; Narosa Publishing House: Madras (India), 2002; pp. 184-205.

(C) 2005 by MDPI (http://www.mdpi.org). Reproduction is permitted for noncommercial purposes. 